\title{
Nanoscale
}

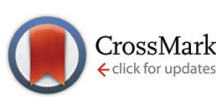

Cite this: Nanoscale, 2015, 7, 1145

Received 17th October 2014, Accepted 10th November 2014

DOI: $10.1039 / c 4 n r 06146 b$

www.rsc.org/nanoscale

\section{Synthesis and photophysical properties of new catenated electron donor-acceptor materials with magnesium and free base porphyrins as donors and $\mathrm{C}_{60}$ as the acceptor}

Sabrina V. Kirner, ${ }^{a}$ Dirk M. Guldi, ${ }^{* a}$ Jackson D. Megiatto, Jr. $\dagger^{\text {b }}$ and David I. Schuster ${ }^{\star b}$

A new series of nanoscale electron donor-acceptor systems with [2]catenane architectures has been synthesized, incorporating magnesium porphyrin $(\mathrm{MgP})$ or free base porphyrin $\left(\mathrm{H}_{2} \mathrm{P}\right)$ as electron donor and $\mathrm{C}_{60}$ as electron acceptor, surrounding a central tetrahedral $\mathrm{Cu}(\mathrm{I})-1,10$-phenanthroline (phen) complex. Model catenated compounds incorporating only one or none of these photoactive moieties were also prepared. The synthesis involved the use of Sauvage's metal template protocol in combination with the 1,3-dipolar cycloaddition of azides and alkynes ("click chemistry"), as in other recent reports from our laboratories. Ground state electron interactions between the individual constituents was probed using electrochemistry and UV-vis absorption spectroscopy, while events occurring following photoexcitation in tetrahydrofuran (under both aerobic and anaerobic conditions) at various wavelengths were followed by means of time-resolved transient absorption and emission spectroscopies on the femtosecond and nanosecond time scales, respectively, complemented by measurements of quantum yields for generation of singlet oxygen. From similar studies with model catenates containing one or neither of the chromophores, the events following photoexcitation could be elucidated. The results were compared with those previously reported for analogous catenates based on zinc porphyrin (ZnP). It was determined that a series of energy transfer (EnT) and electron transfer (ET) processes take place in the present catenates, ultimately generating long-distance charge separated (CS) states involving oxidized porphyrin and reduced $\mathrm{C}_{60}$ moieties, with lifetimes ranging from 400 to 1060 nanoseconds. Shorter lived short-distance CS states possessing oxidized copper complexes and reduced $C_{60}$, with lifetimes ranging from 15 to 60 ns, were formed en route to the long-distance CS states. The dynamics of the ET processes were analyzed in terms of their thermodynamic driving forces. It was clear that intramolecular back ET was occurring in the inverted region of the Marcus parabola correlating rates and driving forces for electron transfer processes. In addition, evidence for triplet excited states as a product of either incomplete ET or back ET was found. The differences in behavior of the three catenates upon photoexcitation are analyzed in terms of the energy levels of the various intermediate states and the driving forces for EnT and ET processes.

\section{Introduction}

In natural photosynthesis the energy of sunlight is converted into chemical energy by a cascade of short-range energy (EnT) and electron transfer (ET) processes. Crucial for efficient EnT and ET is the spatial arrangement of the various light harvest-

\footnotetext{
${ }^{a}$ Department of Chemistry and Pharmacy and Interdisciplinary Center for Molecular Materials, Friedrich-Alexander-Universität Erlangen-Nürnberg, D-91058 Erlangen, Germany.E-mail: dirk.guldi@fau.de

${ }^{b}$ Department of Chemistry, New York University, New York, NY 10003, USA. E-mail: david.schuster@nyu.edu

$\dagger$ Present address: Institute of Chemistry, University of Campinas, PO Box 6154, Campinas, SP, 13084-861, Brazil.
}

ing antennae and the photosynthetic reaction center. ${ }^{1-6}$ To mimic the complex photosynthetic process, simpler model artificial photosynthetic systems have been investigated. ${ }^{7}$ One approach that provides a suitable arrangement of the chromophores is the use of mechanically interlocked rotaxanes and catenanes with attached electron donors and electron acceptors. ${ }^{8-12}$ Sauvage's Cu(I) template synthesis ${ }^{13-17}$ assures a rigid structure of the catenates, due to a $\mathrm{Cu}-1,10$-phenanthroline (phen) $\left(\left[\mathrm{Cu}(\text { phen })_{2}\right]^{+}\right)$core, in which two rings become linked as a result of tetrahedral complexation of two phens to $\mathrm{Cu}(\mathrm{I})$. Thus, a fixed distance between electron donor and electron acceptor is achieved, yielding relatively long lived charge separated states (CSS) upon irradiation. ${ }^{18,19}$ In spite of the central $\left[\mathrm{Cu}(\text { phen })_{2}\right]^{+}$core, corresponding rotaxanes remain 
conformationally flexible due to the unclosed ring. Flamigni et al. ${ }^{18,19}$ investigated the electron transfer properties of catenanes and rotaxanes with attached porphyrins, which are known for their excellent light harvesting and electrochemical characteristics. In their studies, zinc porphyrin (ZnP) served as the electron donor, while $\mathrm{Au}(\mathrm{III})$ porphyrin $\left(\mathrm{AuP}^{+}\right)$functioned as the electron acceptor. Schuster, Guldi and coworkers replaced $\mathrm{AuP}^{+}$with $\mathrm{C}_{60}$ as the electron acceptor in catenane and rotaxane architectures, while $\mathrm{ZnP}$ was retained as the electron donor. ${ }^{20-26}$ The main advantage of $\mathrm{C}_{60}$ compared to $\mathrm{AuP}^{+}$ is the much longer CSS lifetime in the corresponding $\mathrm{ZnP} / \mathrm{C}_{60}$ conjugates. ${ }^{20-26}$ Firstly, the internal reorganization energy $\lambda$ of $\mathrm{C}_{60}$ in electron transfer reactions is very small, due to the rigid structure of $\mathrm{C}_{60} \cdot{ }^{27}$ Secondly, poor solvation of $\mathrm{C}_{60}$ in both polar and nonpolar solvents results in very small values of the external reorganization energy even in the presence of strong electronic interactions in the ground state leading, for example, to exciplex formation..$^{28,29}$ Marcus theory ${ }^{30,31}$ predicts that small values of $\lambda$ will shift the back ET into the so-called Marcus inverted region, where higher values of the exergonic free energy for back ET are accompanied by slower rates for the process, as is the case in natural photosynthesis. ${ }^{2,32-34}$ It is well established that long lived CSS are observed for a large variety of materials, in which $\mathrm{C}_{60}$ is the electron acceptor in electron donor-acceptor systems, in which porphyrins, phthalocyanines and other electron donors are linked either covalently ${ }^{35}$ or mechanically ${ }^{20-26}$ to $\mathrm{C}_{60}$.

The present work ties in with our previous study of the zinc porphyrin- $\left[\mathrm{Cu}(\text { phen })_{2}\right]-\mathrm{C}_{60}$ catenate - see structure $\mathbf{1 0}$ in Scheme $1 .^{23}$ The aim was to vary the redox potentials and, in turn, the driving force for ET as well as EnT by using magnesium porphyrins $(\mathrm{MgP})$ and free base porphyrins, $\left(\mathrm{H}_{2} \mathrm{P}\right)$ respectively, in place of zinc porphyrins ( $\mathrm{ZnP}$ ). Most importantly, MgPs are much easier to oxidize than the corresponding ZnPs by over $250 \mathrm{mV}$, increasing the driving force for ET reactions to acceptors such as $\mathrm{C}_{60}$ in various types of electron donor-acceptor systems. ${ }^{36}$ There have been only limited reports on electron donor-acceptor systems incorporating MgP as the electron donor and $\mathrm{C}_{60}$ as the electron acceptor. D'Souza and coworkers ${ }^{37-40}$ reported that MgPs exhibit higher fluorescence quantum yields and longer excited state lifetimes than the corresponding ZnPs. From time-resolved absorption and emission studies, they found that rates of intramolecular photoinduced electron transfer from the singlet excited states of $\mathrm{MgP}-\mathrm{C}_{60}$ conjugates were extremely fast, on the order of $10^{10} \mathrm{~s}^{-1}$, and that the quantum yields for electron transfer to generate stabilized CSSs were close to unity. As with the corresponding $\mathrm{ZnP}$ conjugates, back ET rates were much slower than for initial photoinduced ET, by $2-3$ orders of magnitude, ${ }^{12}$ reflecting back ET taking place in the Marcus inverted region. $\mathrm{MgP}$ is closely related to the light harvesting chlorophylls in natural photosynthetic systems. ${ }^{1-6}$ It was therefore of considerable interest to investigate the photophysics of catenated structures incorporating $\mathrm{MgP}$ as electron donor in place of $\mathrm{ZnP}$. As a further structural variant, we also determined the properties of catenated structures, in which $\mathrm{H}_{2} \mathrm{P}$ acts as the electron donor.

These new porphyrin- $\left[\mathrm{Cu}(\text { phen })_{2}\right]-\mathrm{C}_{60}$ catenates were synthesized in the same way as their $\mathrm{ZnP}$ analogs ${ }^{41}$ that is by a combination of 1,3-dipolar cycloaddition of azides and alkynes

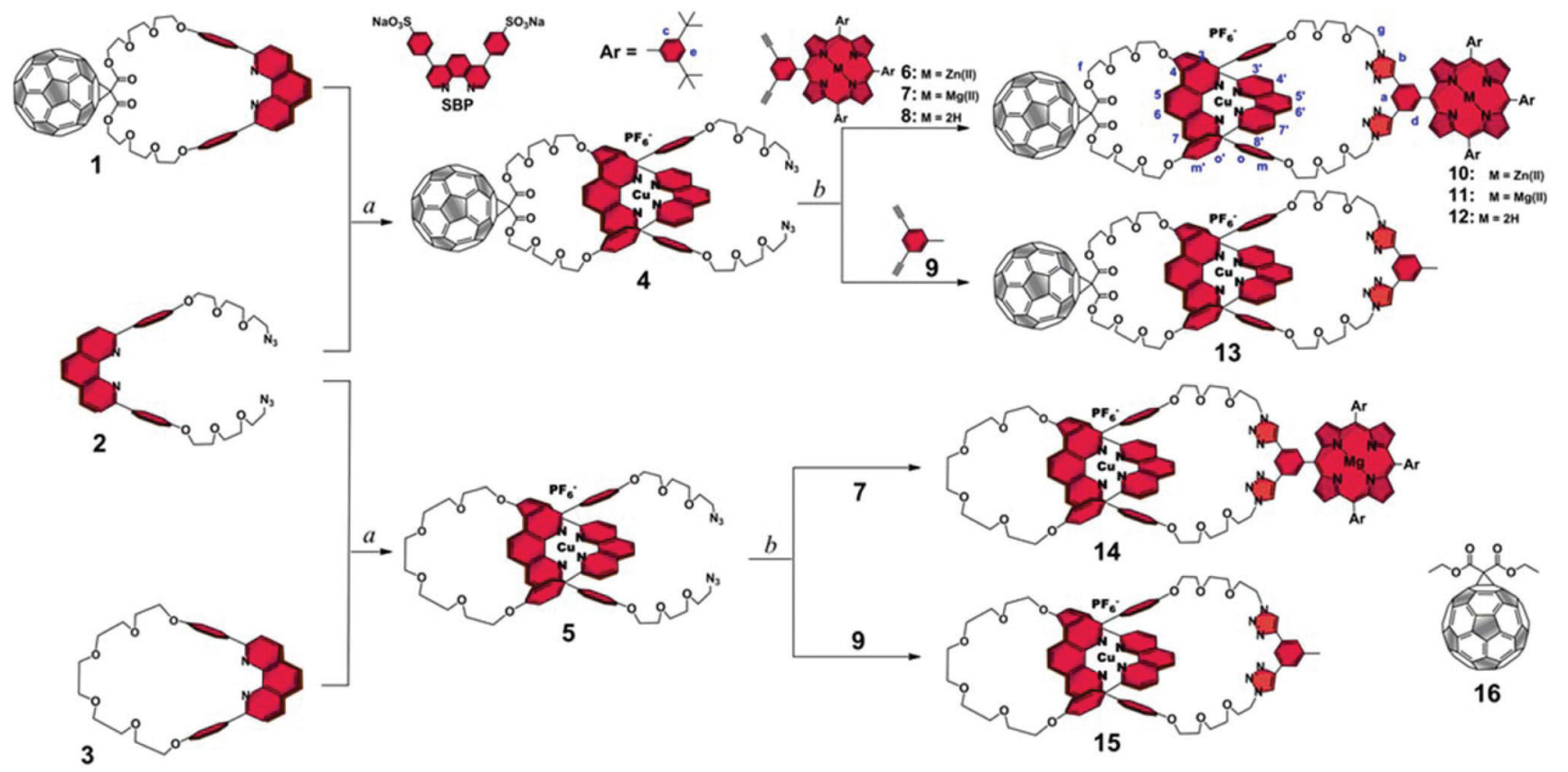

Scheme 1 Synthetic strategy used to afford catenates* and model compounds for the photophysical investigations. * Numbering and lettering in blue on the structures are labels for ${ }^{1} \mathrm{H}$ NMR attributions in the experimental section. Conditions for the syntheses: $(a)\left[\mathrm{Cu}\left(\mathrm{CH}_{3} \mathrm{CN}_{4}\right]\left[\mathrm{PF}_{6}\right], \mathrm{CH}_{2} \mathrm{Cl}_{2}-\right.$ $\mathrm{CH}_{3} \mathrm{CN}, \mathrm{rt}, 3 \mathrm{~h}$, quantitative; (b) Cul, sodium ascorbate, sulfonated bathophenanthroline (SBP), DBU, $\mathrm{H}_{2} \mathrm{O}-\mathrm{EtOH}, \mathrm{rt}, 12 \mathrm{~h}, 55-75 \%$ yields. 
(CuAAC or "click" reaction) $)^{42-44}$ and Sauvage's Cu(I) template protocol. ${ }^{13-17}$ The new electron donor-acceptor systems were thoroughly characterized with respect to their spectroscopic, electrochemical, and photophysical properties. Furthermore, model [2]-catenates lacking either porphyrins, $\mathrm{C}_{60}$ or both served as reference systems. Finally, the three porphyrin$\left[\mathrm{Cu}(\text { phen })_{2}\right]-\mathrm{C}_{60}$ catenates were compared regarding their charge transfer properties upon photoexcitation, namely their CSS lifetimes and the change in efficiency of ET due to the differences in redox potentials and thermodynamic driving forces.

\section{Results and discussion}

\section{Synthesis}

The catenates reported in this work were prepared following our previously reported synthetic strategy based on the combination of Sauvage's $\mathrm{Cu}(\mathrm{I})$ template approach ${ }^{13-16}$ and the $\mathrm{Cu}(\mathrm{I})$ catalyzed 1,3-dipolar cycloaddition of azides and alkynes (CuAAC or "click" reaction) - see Scheme $1 .^{42-44}$ Briefly, $\mathrm{C}_{60}$-macrocycle $\mathbf{1}$ was dissolved in dichloromethane and a solution of $\left[\mathrm{Cu}\left(\mathrm{CH}_{3} \mathrm{CN}\right)_{4}\right]\left[\mathrm{PF}_{6}\right]$ in acetonitrile was added to it. The reaction mixture was stirred at room temperature for 30 minutes under a nitrogen atmosphere. Phen thread 2 was added as a solid to the mixture and the resulting solution was stirred for 3 hours to quantitatively yield pseudorotaxane 4 . The unsubstituted pseudo-rotaxane $\mathbf{5}$ was synthesized from appropriate precursors in a similar fashion.

The biggest challenge in the synthesis of the present catenates was the macrocyclization reaction. Although the "click reaction" has proven to be an excellent protocol to prepare many catenanes and $\left[\mathrm{Cu}(\mathrm{phen})_{2}\right]^{+}$-based catenates, in our case $\mathrm{Cu}(\mathrm{I})$ ions might become a synthetic problem as the appended free base porphyrin could potentially coordinate with the catalytic $\mathrm{Cu}$ ions. Upon removal of the catalytic $\mathrm{Cu}$ ions from the reaction medium, the "double click" macrocyclization reaction would probably not occur. Furthermore, coordination of $\mathrm{Cu}$ ions to the appended group on the porphyrin would lead to copper contamination of the samples, complicating spectroscopic characterization and the photophysical investigation of our catenates. Thus, the synthesis of catenate 12, which bears $\mathrm{H}_{2} \mathrm{P}$, was a major challenge using "click" chemistry. For catenates $\mathbf{1 0}, \mathbf{1 1}$, and $\mathbf{1 4}$, deleterious transmetallation reactions might lead to copper contamination of the catenates as well. To circumvent these synthetic challenges, we used our special "click brew" catalyst, which contains sulfonated bathophenanthroline (SBP) as an auxiliary ligand. ${ }^{45,46}$ SBP has two beneficial effects: On one hand, it is known to enhance the "click" reaction kinetics by stabilizing the $\mathrm{Cu}(\mathrm{I})$ catalytic species, which is crucial for the high-yield synthesis of catenates under kinetic control, as in the present case. On the other hand, SBP also sequesters adventitious $\mathrm{Cu}(\mathrm{I})$ ions from the reaction medium, thus preventing copper contamination of the porphyrin catenates. Indeed, the target catenates 10, 11, 12, and 14 were successfully prepared and isolated following the usual

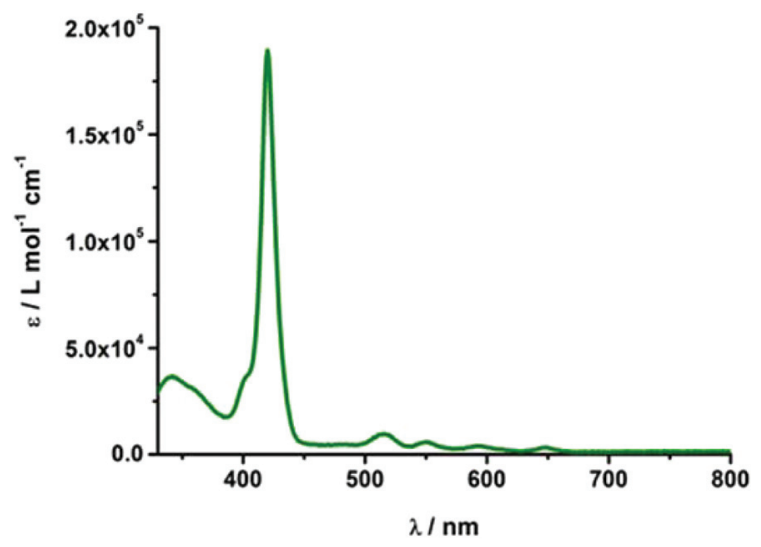

Fig. 1 Absorption spectrum of catenate 12 in THF at room temperature.

workup protocols and chromatographic purification. The less problematic catenates $\mathbf{1 3}$ and 15, which do not contain porphyrins were prepared using the same strategy.

${ }^{1} \mathrm{H}$ NMR analysis confirmed the structures of the new catenates. The ${ }^{1} \mathrm{H}$ NMR spectrum of $\mathbf{1 1}$ is virtually identical to that reported previously ${ }^{23}$ for catenate 10, suggesting that substitution of $\mathrm{Mg}$ (II) for $\mathrm{Zn}$ (II) in the porphyrin core does not cause conformational changes in the catenate structure. The presence of sharp peaks in the ${ }^{1} \mathrm{H}$ NMR spectrum of $\mathbf{1 1}$ confirmed that our "click brew" precluded the transmetallation reaction during the "double click" macrocyclization reaction, as the residual paramagnetic $\mathrm{Cu}$ (II) in the porphyrin core would cause peak broadening in the ${ }^{1} \mathrm{H}$ NMR spectra. The same is true for model catenate $\mathbf{1 4}$. In the case of catenate 12 , the ${ }^{1} \mathrm{H}$ NMR spectrum presented the same sharp peaks as those observed for catenates $\mathbf{1 0}$ and $\mathbf{1 1}$, with an extra resonance at $-2.54 \mathrm{ppm}$ which is attributed to the inner protons of the freebase porphyrin moiety. ${ }^{47}$ Furthermore, the absorption spectrum of free base catenate $\mathbf{1 2}$ (Fig. 1) clearly shows absorption maxima at $420 \mathrm{~nm}$ for the Soret and at 515, 550, 594 and $649 \mathrm{~nm}$ for the four Q-bands, which are typical values for free base porphyrins. ${ }^{7}$ MALDI-TOF analysis provided further support for the structure assignment to catenates 11, 12 and 14. The characteristic general pattern of [2]catenates in mass spectrometry features the molecular ion as well as ion peaks corresponding to the two ring components due to fragmentation of the interlocked structure during the ionization process; this pattern was indeed observed in the MALDI-TOF spectra of catenates 11, 12, and 14. These findings demonstrate that our "click brew" is a suitable medium to catalyze CuAAC reactions, while simultaneously preventing copper contamination of the porphyrin moieties.

\section{Ground state interactions}

Electrochemistry. In order to investigate the redox properties of catenates $\mathbf{1 1}$ and $\mathbf{1 2}$ as well as the model compounds, square wave voltammetry and differential pulse voltammetry experiments were carried out in dichloromethane (DCM) as solvent in the presence of $0.1 \mathrm{M}$ tetrabutylammonium hexafluorophosphate $\left(\mathrm{TBAFPF}_{6}\right)$ as supporting 
Table 1 Oxidation and reduction potentials of all compounds studied. All values (V) are relative to $\mathrm{Fc}_{\mathrm{Fc}}{ }^{+}$as internal reference. Electrolyte: $0.1 \mathrm{M}$ TBAFPF $_{6}$ in dichloromethane (DCM) or ortho-dichlorobenzene (o-DCB). $\mathrm{P}=$ porphyrin

\begin{tabular}{|c|c|c|c|c|c|c|c|}
\hline & Solvent & \multicolumn{3}{|c|}{ Oxidation } & \multicolumn{3}{|l|}{ Reduction } \\
\hline $7^{37}$ & $o-\mathrm{DCB}$ & 0.46 & 0.07 & - & - & - & - \\
\hline $8^{50}$ & $o-\mathrm{DCB}$ & 0.79 & 0.53 & - & - & - & - \\
\hline $10^{23}$ & $o$-DCB & - & 0.18 & 0.18 & -1.12 & -1.48 & -1.96 \\
\hline 11 & $o$-DCB & - & -0.05 & 0.23 & -1.19 & -1.42 & - \\
\hline $15^{22}$ & $o$-DCB & - & - & 0.16 & - & - & - \\
\hline 16 & DCM & - & - & - & -1.06 & -1.44 & -1.88 \\
\hline
\end{tabular}

electrolyte and ferrocene/ferrocenium as internal reference. Table 1 summarizes the electrochemical data.

While the $\mathrm{C}_{60}$ malonate reference 16 was inactive under oxidative conditions, three one electron steps were observed under reductive conditions at $-1.06,-1.44$, and $-1.88 \mathrm{~V}$, resembling the trend found for pristine $\mathrm{C}_{60} \cdot{ }^{48,49}$ Due to the partial loss of $\pi$-conjugation in $\mathbf{1 6}$, a shift towards more negative values for the reduction processes is observed when compared to those of pristine $\mathrm{C}_{60}$. As is known from the literature, MgP exhibits two one electron oxidation steps at +0.07 and $+0.46 \mathrm{~V}^{37} \mathrm{H}_{2} \mathrm{P}$, in contrast, is harder to oxidize, with oxidation potentials of +0.53 and $+0.79 \mathrm{~V} .{ }^{50}$ Model catenate 15 reveals a single oxidation process at $+0.16 \mathrm{~V}$, which correlates with the one-electron oxidation of the copper center, namely $\left[\mathrm{Cu}(\text { phen })_{2}\right]^{+} /\left[\mathrm{Cu}(\text { phen })_{2}\right]^{2+} \cdot{ }^{18,23} \quad \mathrm{C}_{60}-\left[\mathrm{Cu}(\text { phen })_{2}\right]^{+} \quad$ catenate model 13 shows three one electron reductions in the cathodic range at $-1.12,-1.48$, and $-1.96 \mathrm{~V}$, corresponding to $\mathrm{C}_{60}$. In the anodic range, the oxidation of $\left[\mathrm{Cu}(\text { phen })_{2}\right]^{+}$is observed at $+0.16 \mathrm{~V}$. Thus, the presence of $\mathrm{C}_{60}$ has no notable impact on the $\left[\mathrm{Cu}(\mathrm{phen})_{2}\right]^{+}$oxidation. Overall, catenate 11 exhibits similar behavior as catenate model 13 and MgP reference 7. In particular, two one electron reductions are detected within the electrochemical window of the solvent at -1.19 and $-1.42 \mathrm{~V}$. Both are assigned to $\mathrm{C}_{60}$. The anodic scan reveals an oxidation at $+0.23 \mathrm{~V}$, which corresponds to a $\left[\mathrm{Cu}(\text { phen })_{2}\right]^{+}$centered process, and an additional peak at $-0.05 \mathrm{~V} v s$. $\mathrm{Fc} / \mathrm{Fc}^{+}$. The latter stems from the first MgP oxidation. Finally, catenate 12 gives rise to the same features as those summarized for catenate 11. In the cathodic scan, two $\mathrm{C}_{60}$ reductions are detected at -1.07 and $-1.46 \mathrm{~V}$. The anodic process reveals the $\left[\mathrm{Cu}(\text { phen })_{2}\right]^{+}$oxidation at $+0.25 \mathrm{~V}$ and the first $\mathrm{H}_{2} \mathrm{P}$ oxidation at $+0.38 \mathrm{~V}$. In both, $\mathrm{MgP}$ as well as $\mathrm{H}_{2} \mathrm{P}$ catenates 11 and 12, the oxidation potentials of the porphyrin are shifted to lower potentials compared to the corresponding porphyrin references 7 and 8 , while the $\left[\mathrm{Cu}(\text { phen })_{2}\right]^{+}$peaks are clearly shifted towards more positive values compared to reference 15 . The $\mathrm{C}_{60}$ reductions remain nearly the same in both 11 and 12 when compared to $\mathrm{C}_{60}$ malonate reference $\mathbf{1 6}$.

UV-Vis absorption. The absorption spectra of the investigated systems show the typical features of the individual components. In Fig. 2, the spectra of MgP-catenates 11, and 14 as

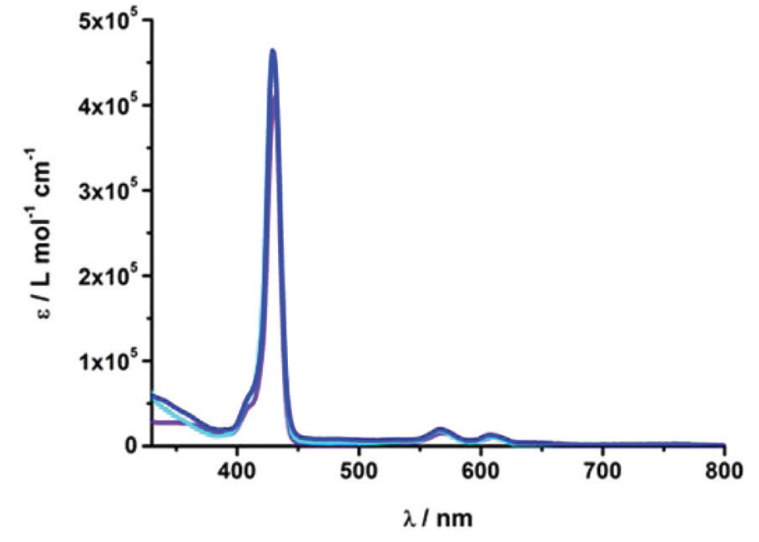

Fig. 2 Absorption spectra of catenates 11 (blue), 14 (cyan), and MgP reference 7 (violet) in THF at room temperature.

well as reference 7 are dominated by the porphyrin's Soret band at $430 \mathrm{~nm}$ and Q-bands, which appear between 550 and $650 \mathrm{~nm}$, respectively. The absorption between 300 and $400 \mathrm{~nm}$ corresponds to $\left[\mathrm{Cu}(\text { phen })_{2}\right]^{+}$in 11 and 14 and $\mathrm{C}_{60}$ in 11. Importantly, the extinction coefficients, which are comparable to those seen for the references, suggest the lack of significant intramolecular electronic interactions in the ground state. A similar conclusion is gathered for $\mathrm{H}_{2} \mathrm{P}$-catenate 12 see Fig. 1. Nevertheless, the main difference in $\mathbf{1 4}$ compared to catenate $\mathbf{1 1}$ is the presence of four rather than just two Q-bands in the region between 500 and $660 \mathrm{~nm}$ due to the different symmetry in $\mathrm{H}_{2} \mathrm{P}$. Furthermore, the Soret band is shifted to lower wavelengths, namely to $420 \mathrm{~nm}$.

\section{Excited state interactions}

To investigate the electronic interactions between the different photoactive components in the excited state, steady state as well as time resolved emission and transient absorption on the femto- and nanosecond time scales were performed with catenates 11-15 and porphyrins 7 and $\mathbf{8}$ in solvents of different polarity, namely tetrahydrofuran (THF) and benzonitrile (PhCN). The data from room temperature measurements are summarized in Table 2. 
Table 2 Fluorescence parameters at room temperature (293 K)

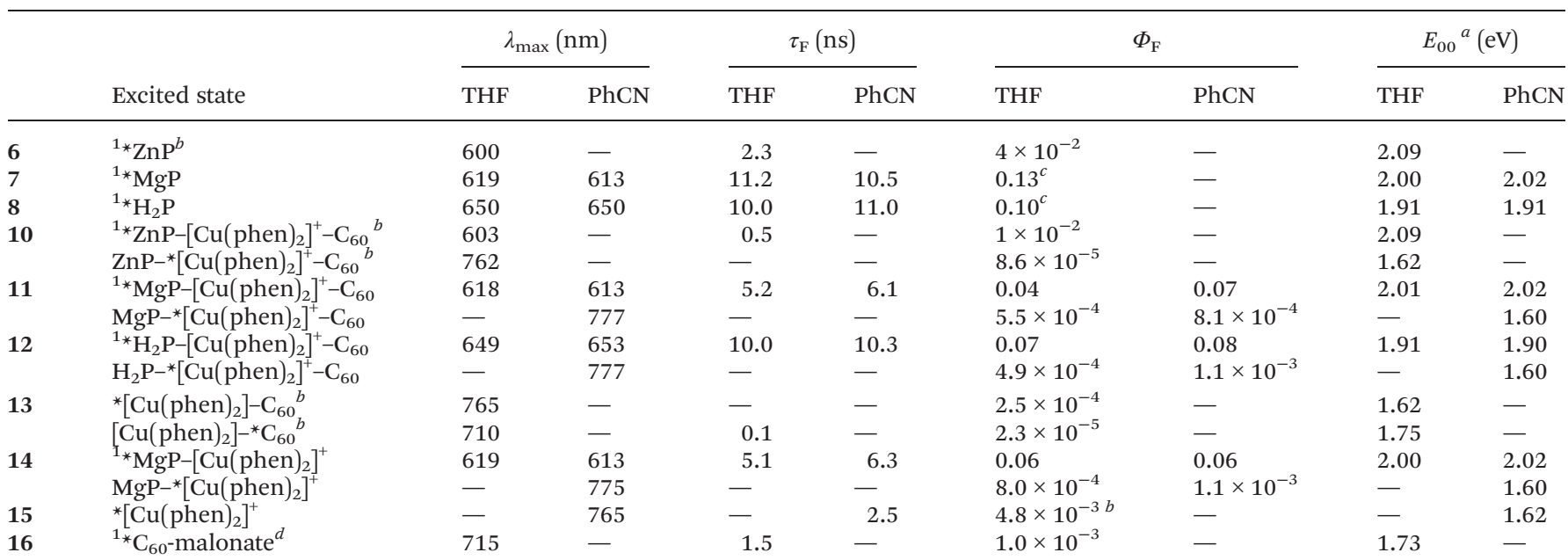

${ }^{a}$ Energy of the corresponding excited state relative to the ground state, calculated from the emission maximum $\left(\lambda_{\max }\right) .{ }^{b}$ In dichloromethane, from ref. 23. ${ }^{c}$ In benzene, from ref. 51. ${ }^{d}$ In chloroform, from ref. 23.
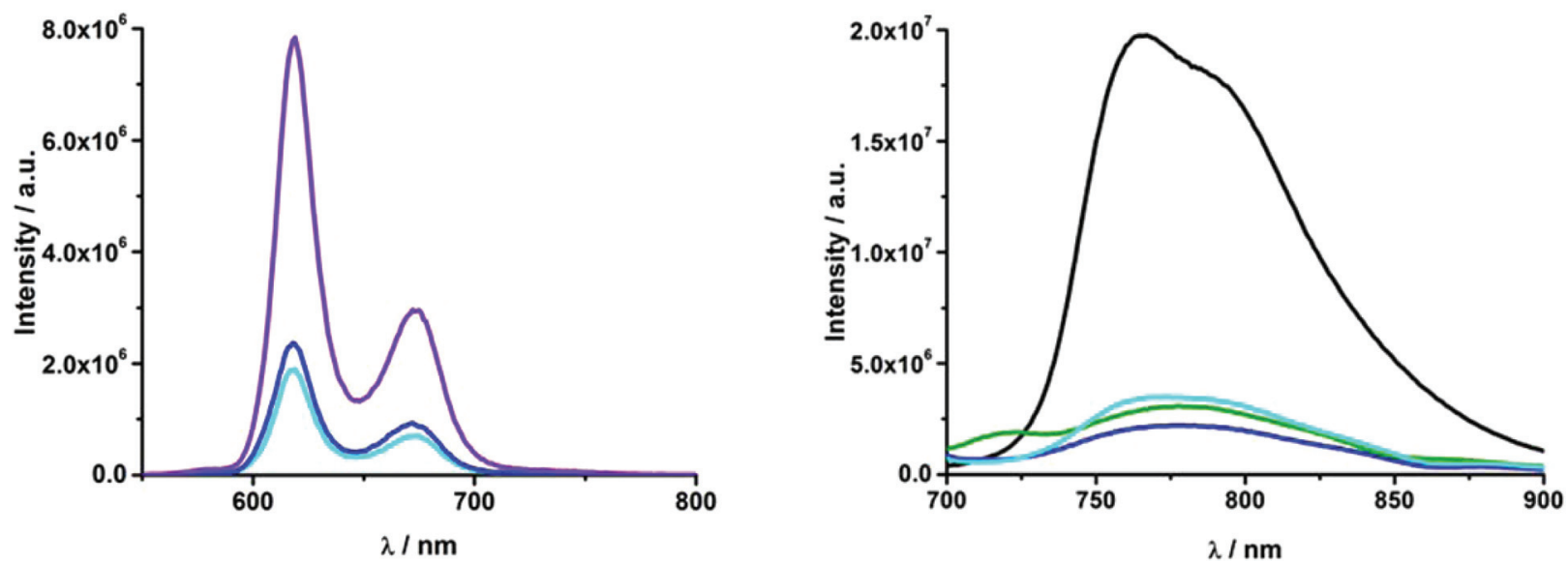

Fig. 3 Left: Emission spectra of MgP (violet), and catenates 11 (blue) and 14 (cyan) in THF upon excitation at $430 \mathrm{~nm}(\mathrm{OD}=0.075)$ at room temperature. Right: Emission spectra of $\left[\mathrm{Cu}(\text { phen) }]_{2}\right]^{+} 15$ (black), and catenates 11 (blue), 12 (olive) and 14 (cyan) in PhCN upon excitation at $320 \mathrm{~nm}(\mathrm{OD}=$ $0.07)$ at room temperature.

Emission spectroscopy. The strongest fluorophores among the references are the porphyrins with fluorescence quantum yields $\left(\Phi_{\mathrm{F}}\right)$ of $0.13(\mathrm{MgP})$ and $0.10\left(\mathrm{H}_{2} \mathrm{P}\right) \cdot{ }^{52} \mathrm{MgP}$ reference 7 shows emission maxima at 620 and $670 \mathrm{~nm}$ in THF while $\mathrm{H}_{2} \mathrm{P}$ reference 8 exhibits red-shifted emission with maxima at 650 and $720 \mathrm{~nm}$ (see Fig. 3). In time resolved emission experiments, lifetimes of 11.2 and 10 ns were determined for 7 and 8, respectively, in benzene, as shown in Table 2 . $\left[\mathrm{Cu}(\text { phen })_{2}\right]^{+}$ reference 15 reveals much weaker emission. In PhCN, the MLCT emission has a lifetime of $2.5 \mathrm{~ns}$ and a quantum yield of $4.8 \times 10^{-3}$ at $765 \mathrm{~nm}-$ Table 2 and Fig. 3. The weakest emission was observed for $\mathrm{C}_{60}$-malonate $\mathbf{1 6}$ with a maximum at $715 \mathrm{~nm}$, a fluorescence quantum yield of $1.0 \times 10^{-3}$, and a fluorescence lifetime of $1.48 \mathrm{~ns}$ in $\mathrm{CHCl}_{3}{ }^{51}$

Compared to the porphyrin references 7 and 8 , catenates 11, 12, and 14 show quenched emission. Fig. 3 depicts the emission of catenates $\mathbf{1 1}$ and $\mathbf{1 4}$ in THF solutions with equal absorptions at the $430 \mathrm{~nm}$ excitation wavelength. Importantly, two emission maxima at 620 and $680 \mathrm{~nm}$ are seen. Emissions in these catenates are quenched by approximately a factor of 2 in comparison to reference 7 - Table 2 . The emission of catenate 12 is $30 \mathrm{~nm}$ red-shifted, which is a characteristic of free base porphyrins, ${ }^{7}$ and is also quenched. The latter amounts to about $20 \%$ relative to reference 8 . In time-resolved emission experiments, lifetimes of $6.1 \mathrm{~ns}$ for 11, $10.3 \mathrm{~ns}$ for 12 and $6.3 \mathrm{~ns}$ for 14 were determined in PhCN compared to $10.5 \mathrm{~ns}$ for 7 and $11.0 \mathrm{~ns}$ for $\mathbf{8}$. Since the porphyrin emission is quenched not only in catenates $\mathbf{1 1}$ and $\mathbf{1 2}$, but also in catenate reference 14, which lacks $\mathrm{C}_{60}$, we ascribe the underlying process to an EnT from either $\mathrm{MgP}$ or $\mathrm{H}_{2} \mathrm{P}$ to $\left[\mathrm{Cu}(\text { phen })_{2}\right]^{+}$. Based on thermodynamics, ET is unlikely to happen between $\mathrm{MgP} / \mathrm{H}_{2} \mathrm{P}$ and $\left[\mathrm{Cu}(\text { phen })_{2}\right]^{+}$. Catenates 11, 12, and 14 were also excited at $320 \mathrm{~nm}$, which coincides with the maximum absorption of $\left[\mathrm{Cu}(\text { phen })_{2}\right]^{+}$. The emission spectra with broad features 
Table 3 Singlet oxygen quantum yields $\Phi_{\Delta}$

\begin{tabular}{lll}
\hline Compound & Solvent & $\Phi_{\Delta}$ \\
\hline $\mathbf{7}$ & Benzene & $0.66^{53}$ \\
$\mathbf{8}$ & Benzene & $0.62^{53,54}$ \\
& THF & $0.62^{54}$ \\
$\mathbf{1 1}$ & THF & 0.24 \\
$\mathbf{1 2}$ & THF & 0.34 \\
$\mathbf{1 4}$ & THF & 0.32
\end{tabular}

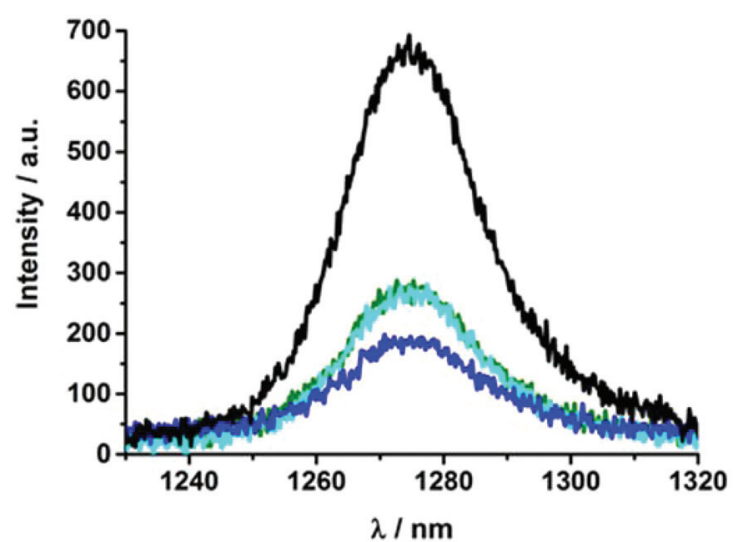

Fig. $4{ }^{1} \mathrm{O}_{2}$ phosphorescence of 8 (black), catenates 11 (blue), 12 (olive), and 14 (cyan) in THF upon excitation at $347 \mathrm{~nm}(\mathrm{OD}=0.045)$ at room temperature.

between 730 and $860 \mathrm{~nm}$ are shown in Fig. 3. The MLCT emission quantum yields of catenates $\mathbf{1 1}, \mathbf{1 2}$, and 14 are on the order of $10^{-4}$, which is approximately one order of magnitude smaller than that recorded for reference $\left[\mathrm{Cu}(\mathrm{phen})_{2}\right]^{+}$catenate 15 (Table 2). A possible rationale is a slow transduction of triplet excited state energy back to either $\mathrm{MgP}$ or $\mathrm{H}_{2} \mathrm{P}$. The weak fluorescence of $\mathrm{C}_{60}$ could not be probed in catenates $\mathbf{1 1}$ and 12, due to strongly overlapping absorption and emission bands.
Singlet oxygen quantum yields. To gain further insight into photoprocesses taking place in catenates 11, 12, and 14, in particular intersystem crossing (ISC) to give triplet excited states, singlet oxygen quantum yields $\left(\Phi_{\Delta}\right)$ were determined using porphyrin 8 in THF as a reference. ${ }^{53,54}$ The results are summarized in Table 3. Compared to reference $8, \mathrm{H}_{2} \mathrm{P}-[\mathrm{Cu}-$ (phen) $]^{+}-\mathrm{C}_{60}$ catenate 12 exhibits a nearly $50 \%$ lower singlet oxygen phosphorescence - Fig. 4. Also $\mathrm{MgP}-\left[\mathrm{Cu}(\text { phen })_{2}\right]^{+}-\mathrm{C}_{60}$ catenate 11 as well as $\mathrm{MgP}-\left[\mathrm{Cu}(\text { phen })_{2}\right]^{+}$catenate 14 show a quenched ${ }^{1} \mathrm{O}_{2}$ quantum yield compared to MgTPP. It is clear that $\mathrm{C}_{60}$ plays an important role, since $\mathbf{1 1}$ displays even lower ${ }^{1} \mathrm{O}_{2}$ phosphorescence than does 14. Furthermore, $\mathrm{MgP}$ has a stronger inhibiting influence on the ISC than $\mathrm{H}_{2} \mathrm{P}$. From these results it is concluded that upon photoexcitation of catenates 11, 12, and 14, alternative deactivation pathways are in competition with ISC. In particular, EnT and ET take place due to the presence of $\left[\mathrm{Cu}(\text { phen })_{2}\right]^{+}$and $\mathrm{C}_{60}$, respectively. Based on these experiments, energy transfer from ${ }^{3 *}\left[\mathrm{Cu}(\text { phen })_{2}\right]^{+}$to $\mathrm{ZnP}, \mathrm{MgP}$ or $\mathrm{H}_{2} \mathrm{P}$ is ruled out, since this would have led to higher singlet oxygen quantum yields, which was not observed.

Transient absorption. To obtain information about the formation and deactivation processes taking place upon photoexcitation of catenates 11-15 and references 7, 8, and 16, transient absorption studies were carried out. Upon $420 \mathrm{~nm}$ excitation of $\mathrm{MgP}$ reference 7 , characteristic differential absorption changes evolve immediately after the laser pulse in THF. An intense transient absorption is observed with a maximum at $460 \mathrm{~nm}$, along with a broad absorption in the 580 to $750 \mathrm{~nm}$ range, which corresponds to the $\mathrm{MgP}$ singlet excited state (Fig. 5). ${ }^{12}$ This absorption decays at a rate of $1 \times 10^{8} \mathrm{~s}^{-1}$ affording the energetically lower lying triplet excited state. The signature of the latter is a $840 \mathrm{~nm}$ absorption maximum, ${ }^{55}$ which develops with kinetics similar to the decay of the MgP singlet absorption at $460 \mathrm{~nm}$. Transient bleaching at 570 and $610 \mathrm{~nm}$ reflects the $\mathrm{MgP}$ Q-band absorption. It is discernible from Fig. 5 that the differential absorption spectra
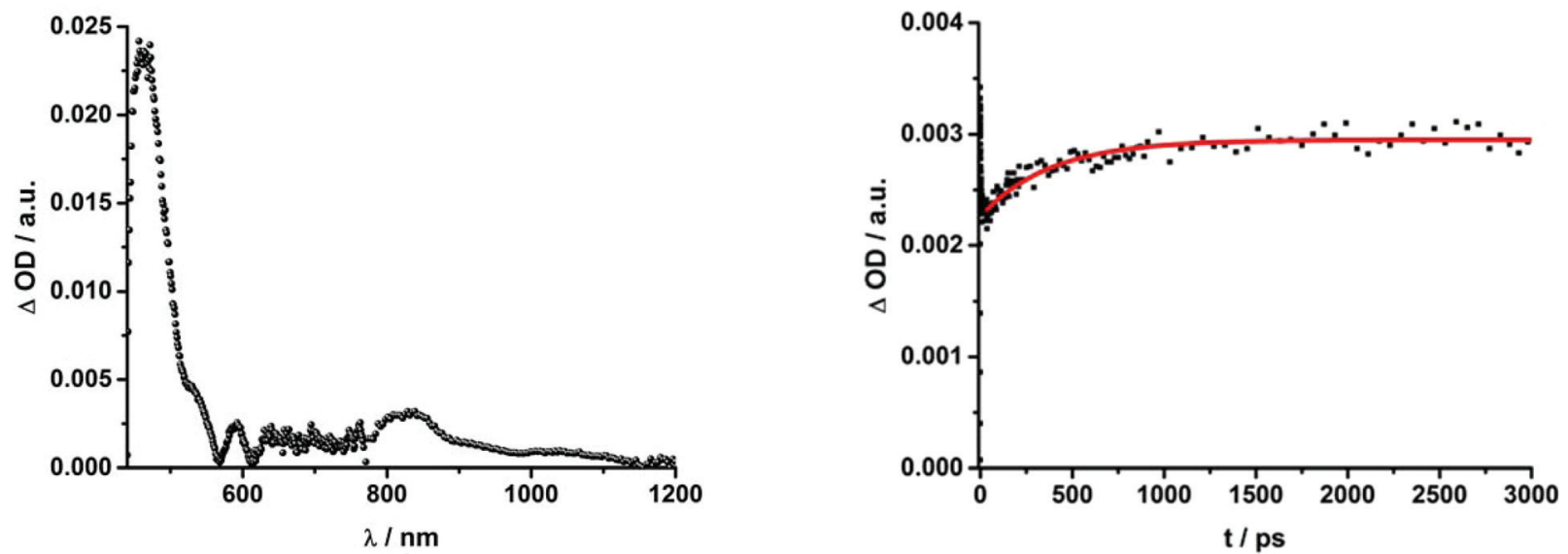

Fig. 5 Left: Differential absorption spectrum (visible and near-infrared) registered upon femtosecond flash photolysis (420 $\mathrm{nm}, 150 \mathrm{~nJ}$ ) of $\mathrm{MgP}$ reference 7 in THF with a time delay of $3.2 \mathrm{~ns}$ at room temperature. Right: Time-absorption profile of MgP at $840 \mathrm{~nm}$, monitoring the intersystem crossing process. 

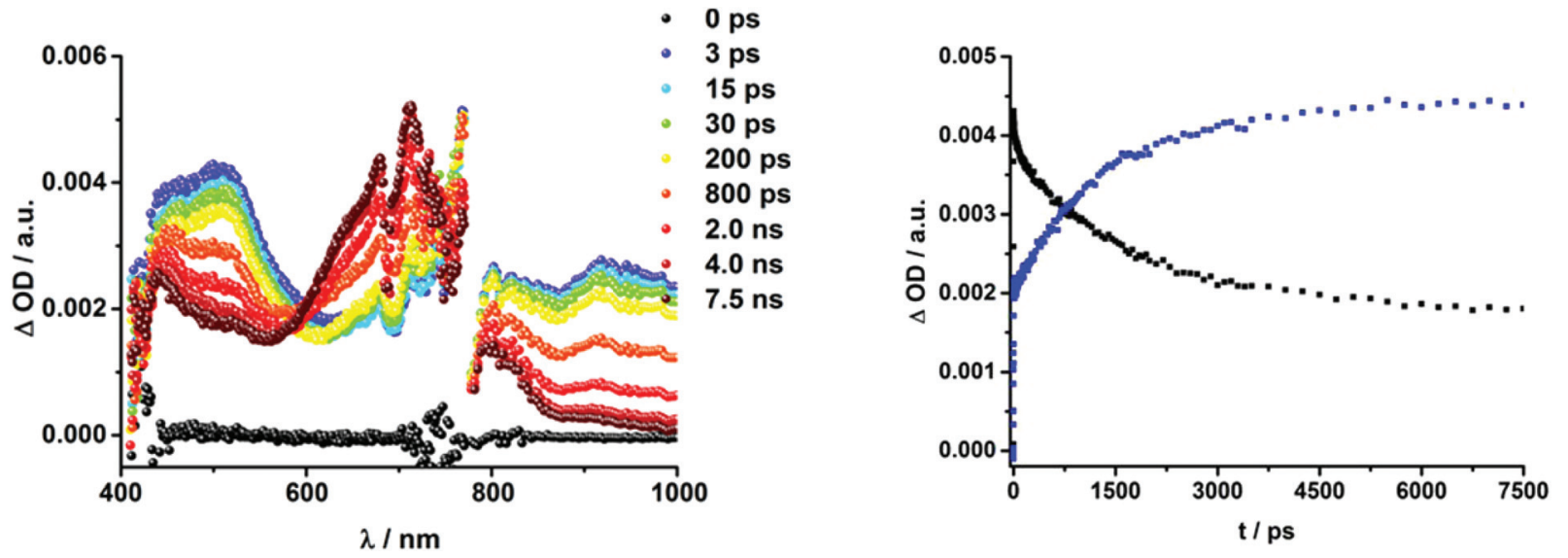

Fig. 6 Left: Differential absorption spectra (visible and near-infrared) registered upon femtosecond flash photolysis ( $387 \mathrm{~nm}, 200 \mathrm{~nJ})$ of $\mathrm{C}_{60}-\mathrm{malo}$ nate 16 in THF with time delays between 0 and $7.5 \mathrm{~ns}$ at room temperature. Right: Time-absorption profiles of $\mathrm{C}_{60}-\mathrm{malonate} 7$ at $510 \mathrm{~nm}$ (black) and $680 \mathrm{~nm}$ (blue), monitoring the intersystem crossing process.
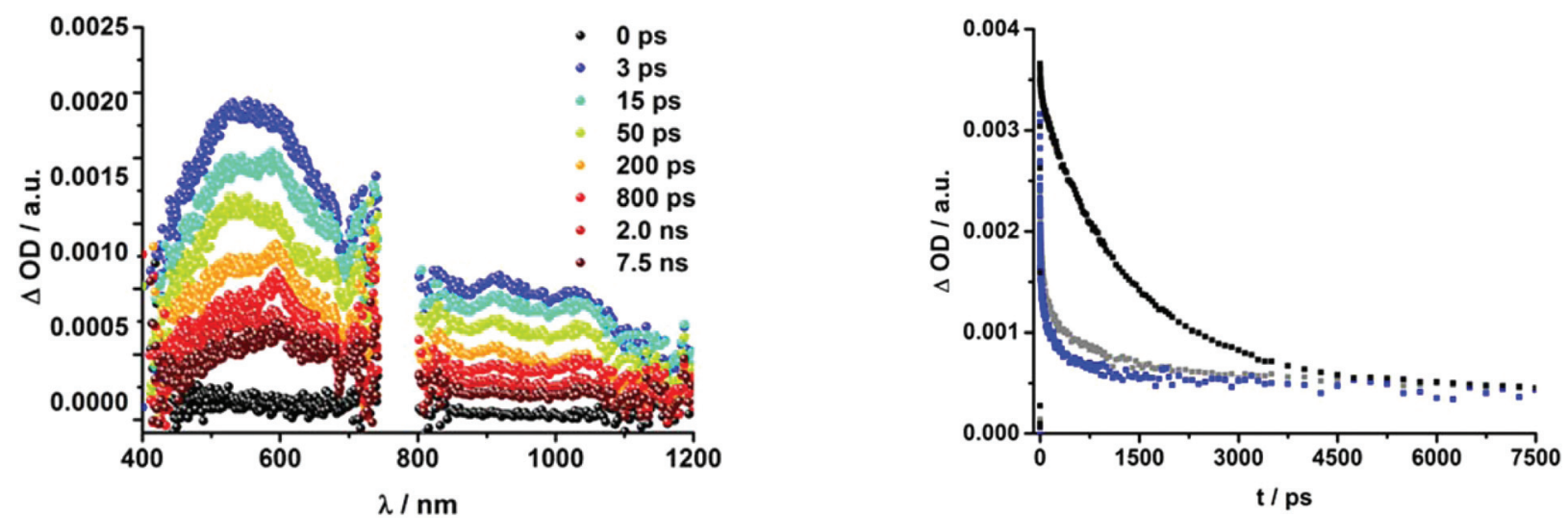

Fig. 7 Left: Differential absorption spectra (visible and near-infrared) registered upon femtosecond flash photolysis (387 $\mathrm{nm}, 200 \mathrm{~nJ}$ ) of $\left[\mathrm{Cu}(\text { phen })_{2}\right]^{+}-\mathrm{C}_{60}$ catenate reference 13 in THF at room temperature with time delays between 0 and 7.5 ns. Right: Time-absorption profiles of catenates 11 (blue) and 13 (grey) as well as $\mathrm{C}_{60}$-malonate 16 (black) at $920 \mathrm{~nm}$, monitoring ET.

after a time delay of 3.2 ns exhibit feature characteristics of both the singlet and triplet excited states of MgP.

For $\mathrm{C}_{60}$-malonate 16, the differential absorption spectra in THF - Fig. 6 - show formation of the singlet excited state upon excitation at $387 \mathrm{~nm}$ with maxima at 510 and $920 \mathrm{~nm}$, which then undergoes nearly quantitative intersystem crossing with a rate constant of $6 \times 10^{8} \mathrm{~s}^{-1}$ to give the energetically lower lying triplet excited state with a characteristic absorption maximum at $720 \mathrm{~nm} .^{23,24}$ Fig. 6 portrays the kinetics of the intersystem crossing process. In complementary nanosecond experiments a triplet lifetime of $23 \mu \mathrm{s}$ was determined in argon-saturated $\mathrm{THF}$, comparable to the value of $20 \mu$ s measured in $\mathrm{PhCN} .^{22}$

Upon excitation of $\left[\mathrm{Cu}(\text { phen })_{2}\right]^{+}$reference catenate 15 at $387 \mathrm{~nm}$ in THF, the characteristic $\left[\mathrm{Cu}(\text { phen })_{2}\right]^{+}$MLCT transient absorption is observed, which includes a broad maximum between 540 and $610 \mathrm{~nm}$ followed by another maximum around $910 \mathrm{~nm} \cdot{ }^{20-24}$ Furthermore, minima at 440 and $700 \mathrm{~nm}$ correspond to the MLCT absorption. It is well established that the singlet excited MLCT state decays within hundreds of femtoseconds to yield the energetically lower lying MLCT triplet excited state. ${ }^{56,57}$ Thus, the observed transient absorption is attributed to the MLCT triplet state, which has a lifetime of 645 ns under these conditions. ${ }^{23}$

Fig. 7 documents that following $387 \mathrm{~nm}$ excitation of $\left[\mathrm{Cu}(\text { phen })_{2}\right]^{+}-\mathrm{C}_{60}$ reference 13 in THF maxima at 530, 590, and $920 \mathrm{~nm}$ evolve, which is consistent with the results noted for reference compounds 15 and 16. In contrast to $\mathrm{C}_{60}$-malonate 16, the excited state of $\mathbf{1 3}$ deactivates rapidly with a rate of $2.5 \times 10^{10} \mathrm{~s}^{-1}$, as a result of the close proximity between $\mathrm{C}_{60}$ and $\left[\mathrm{Cu}(\mathrm{phen})_{2}\right]^{+}$. As seen for 15, the triplet MLCT excited state does not decay completely within the time scale of our experimental setup of 7.5 ns. As a matter of fact, an additional peak is seen in the spectrum of catenate 13 at $1035 \mathrm{~nm}$ corresponding to the one-electron reduced form of $\mathrm{C}_{60}{ }^{33,55}$ indicating that the deactivation of the $\mathrm{C}_{60}$ singlet excited state of $\mathbf{1 3}$ involves ET. On the time scale of the 

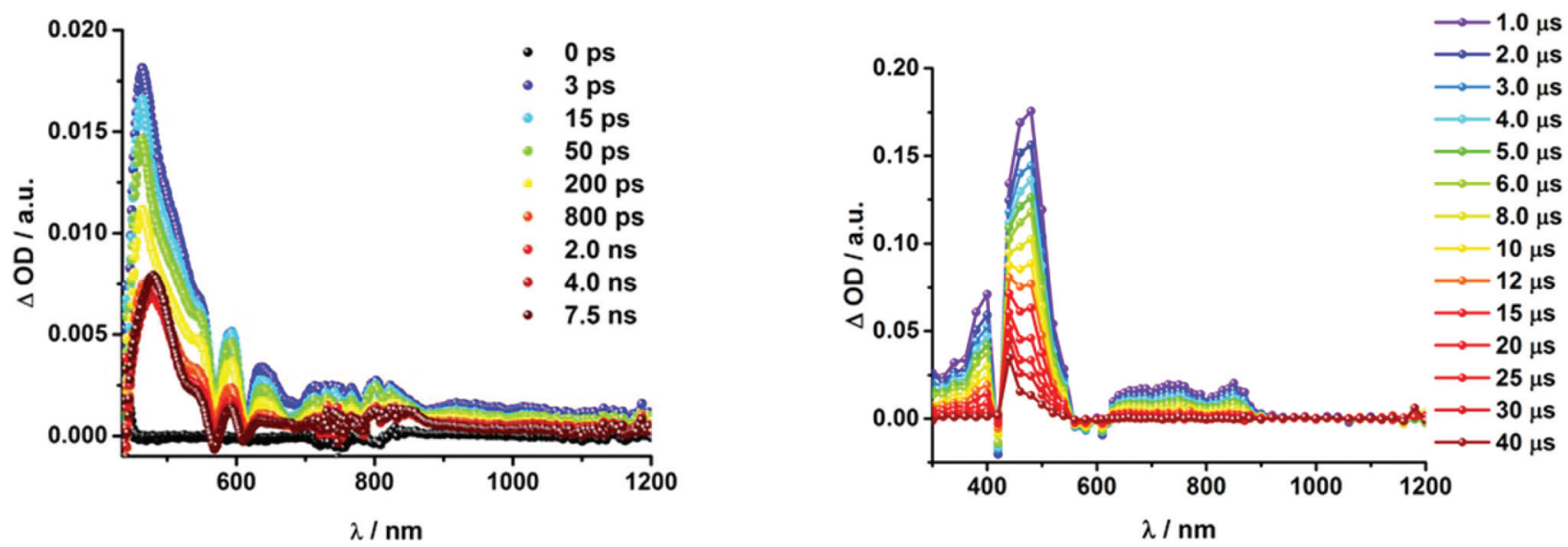

Fig. 8 Left: Differential absorption spectra (visible and near-infrared) registered upon femtosecond flash photolysis (387 nm, $200 \mathrm{~nJ})$ of $\mathrm{MgP}-$ $\left[\mathrm{Cu}(\text { phen })_{2}\right]^{+}$catenate 14 in THF with time delays between 0 and $7.5 \mathrm{~ns}$ at room temperature. Right: Differential absorption spectra (visible and near infrared) registered upon nanosecond flash photolysis $(355 \mathrm{~nm}, 10 \mathrm{~mJ})$ of $\mathrm{MgP}-\left[\mathrm{Cu}(\text { phen })_{2}\right]^{+}$catenate 14 in THF with time delays between 1 and $40 \mu$ s at room temperature.

femtosecond experiments, the $\mathrm{C}_{60}$ radical anion is stable. It was only on the time scale of complementary nanosecond experiments that a lifetime of 100 ns could be determined for the CSS of 13 in THF.

Upon excitation of $\mathrm{MgP}-\left[\mathrm{Cu}(\text { phen })_{2}\right]^{+}$reference catenate 14, at either 387 or $420 \mathrm{~nm}$, the differential absorption spectra are dominated by the MgP singlet excited state, due to the strong porphyrin absorption in this region. As seen for $\mathrm{MgP}$ reference 7, a transient evolves in THF directly after laser excitation that features a maximum at $460 \mathrm{~nm}$, broad transient absorption between 580 and $750 \mathrm{~nm}$, and transient bleaching at 570 and $610 \mathrm{~nm}$ - compare Fig. 5 and 8. In sharp contrast to the MgP reference, the singlet excited state of catenate $\mathbf{1 4}$ undergoes rapid EnT from the singlet excited state of $\mathrm{MgP}$ to the lower lying $\left[\mathrm{Cu}(\text { phen })_{2}\right]^{+}$excited state, as determined by the decay at $460 \mathrm{~nm}$, at a rate of $2.5 \times 10^{9} \mathrm{~s}^{-1}$ in THF (see Fig. 8). Nonetheless, this EnT process is not quantitative as the features of ${ }^{3} \mathrm{MgP}^{*}$ are still discernible in the 480 to $840 \mathrm{~nm}$ region of Fig. 7 .

In addition to the MgP excited states, the transient absorption corresponding to the MLCT triplet excited state is detected at $\sim 950 \mathrm{~nm}$, which decays within 660 ps. In the visible region of the spectrum, the MLCT features are obscured by the much stronger MgP transients. Turning to the nanosecond transient absorption spectra in Fig. 8, right, only the long-lived $(15.8 \mu \mathrm{s})$ features of ${ }^{3} \mathrm{MgP}^{*}$ are discernible in the visible region. We note that the ${ }^{3} \mathrm{MLCT}^{*}$ features could not be clearly identified in these spectra because of their comparably small extinction coefficients and shorter lifetimes, on the order of hundreds of nanoseconds.

$\mathrm{MgP}-\left[\mathrm{Cu}(\text { phen })_{2}\right]^{+}-\mathrm{C}_{60}$ and $\mathrm{H}_{2} \mathrm{P}-\left[\mathrm{Cu}(\text { phen })_{2}\right]^{+}-\mathrm{C}_{60}$ catenates 11 and 12 were also excited at 387 as well as $420 \mathrm{~nm}$ in THF and PhCN. As seen in the aforementioned references the differential absorption spectra are dominated by the fingerprints of $\mathrm{MgP}$ and $\mathrm{H}_{2} \mathrm{P}$. For example, in catenate 11 upon selective excitation of $\mathrm{MgP}$ with a $420 \mathrm{~nm}$ laser pulse, maxima are observed at 465, 590, and $640 \mathrm{~nm}$ and transient bleaching is seen at 570 and $610 \mathrm{~nm}$. All of these features correspond to the MgP singlet excited state (Fig. 9). In analogy to 14, we again observe a faster decay of the MgP singlet excited state than seen for reference 7, consistent with EnT to $\left[\mathrm{Cu}(\text { phen })_{2}\right]^{+}$. Upon $387 \mathrm{~nm}$ excitation of $\mathbf{1 1}$, the features of the $\mathrm{C}_{60}$ singlet excited state develop at $920 \mathrm{~nm}$. Unlike $\mathrm{C}_{60}$ reference $\mathbf{1 6}$, the $\mathrm{C}_{60}$ singlet excited state deactivates in 11 rapidly - Fig. 7 - to yield the one electron reduced form of $\mathrm{C}_{60}$ with its characteristic absorption at $1035 \mathrm{~nm} .^{56,57}$ This species was stable throughout the $7.5 \mathrm{~ns}$ time scale of our experimental setup. In the visible region, the MgP singlet and triplet state absorption again mask the MLCT excited states.

To gain insight into the back ET process, catenate $\mathbf{1 1}$ was excited with a $6 \mathrm{~ns}$ laser pulse at 355 and $532 \mathrm{~nm}$. Regardless of selectively exciting $\mathrm{MgP}$ at $532 \mathrm{~nm}$ or unselectively exciting all components at $355 \mathrm{~nm}$, the visible region of the differential absorption spectra is dominated by the triplet excited state features of MgP, with maxima at 470 and $840 \mathrm{~nm}$ (see Fig. 10).

Furthermore, the 680 and $720 \mathrm{~nm}$ maxima, which are clearly observed in Fig. 10, correspond to the one electron oxidized form of $\mathrm{MgP}$ and the triplet excited state of $\mathrm{C}_{60}$, respectively. Since the spectroscopic signatures of the latter two overlap with each other as well as with that of $\mathrm{MgP}$ triplet excited state, the signature absorption for the one electron oxidized form of MgP becomes evident only upon quenching of the $\mathrm{MgP}$ and $\mathrm{C}_{60}$ triplet excited states by molecular oxygen. This is documented in Fig. 10 and 11. A biexponential fit of the decay at $680 \mathrm{~nm}$ in the presence of oxygen yields a shortlived component of $190 \mathrm{~ns}$ and a long-lived component of 700 ns. The former relates to quenched $\mathrm{C}_{60}$ triplet excited states, while the latter correlates with the one electron oxidized form of MgP. A closer look at the near infrared region allows identification at shorter times of the fingerprint absorption of the one electron reduced form of $\mathrm{C}_{60}$ at $1035 \mathrm{~nm}-$ Fig. 10. The 

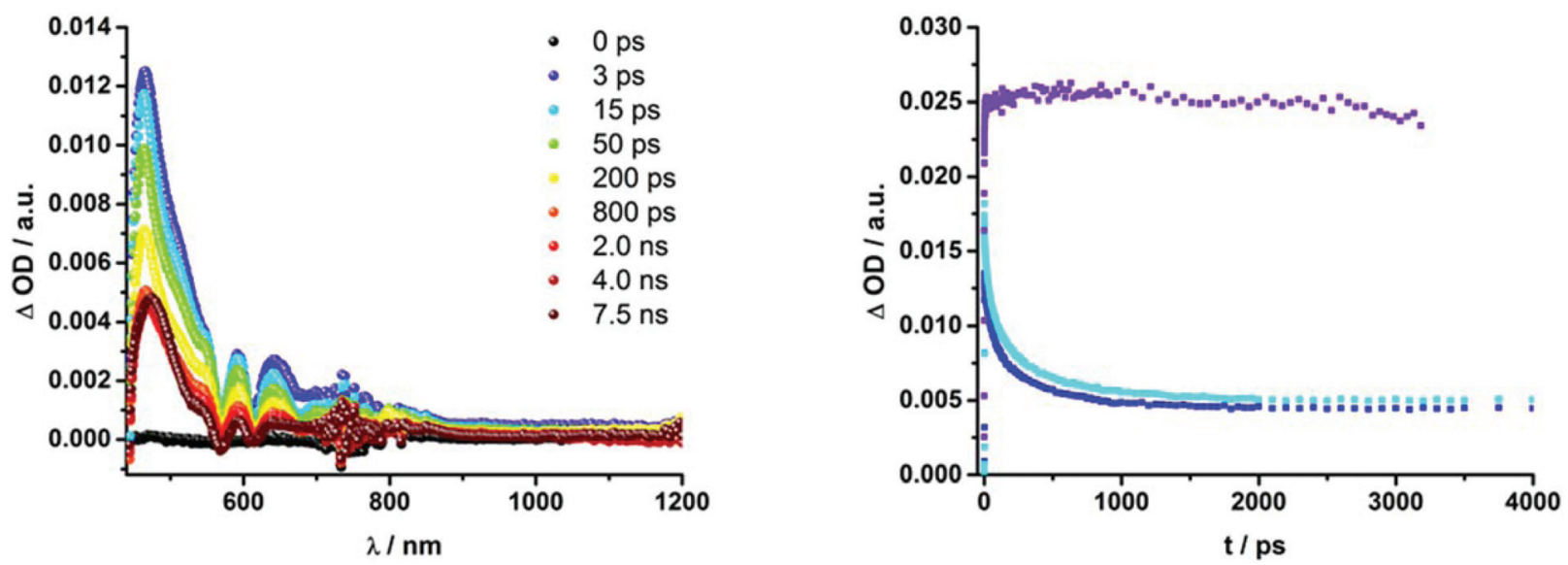

Fig. 9 Left: Differential absorption spectra (visible and near-infrared) registered upon femtosecond flash photolysis (420 nm, $150 \mathrm{~nJ})$ of $\mathrm{MgP}-$ $\left[\mathrm{Cu}(\text { phen })_{2}\right]^{+}-\mathrm{C}_{60}$ catenate 11 in THF with time delays between 0 and $7.5 \mathrm{~ns}$ at room temperature. Right: Time-absorption profiles of catenates 11 (blue) and 14 (cyan) as well as MgP (violet) at $465 \mathrm{~nm}$, monitoring EnT.
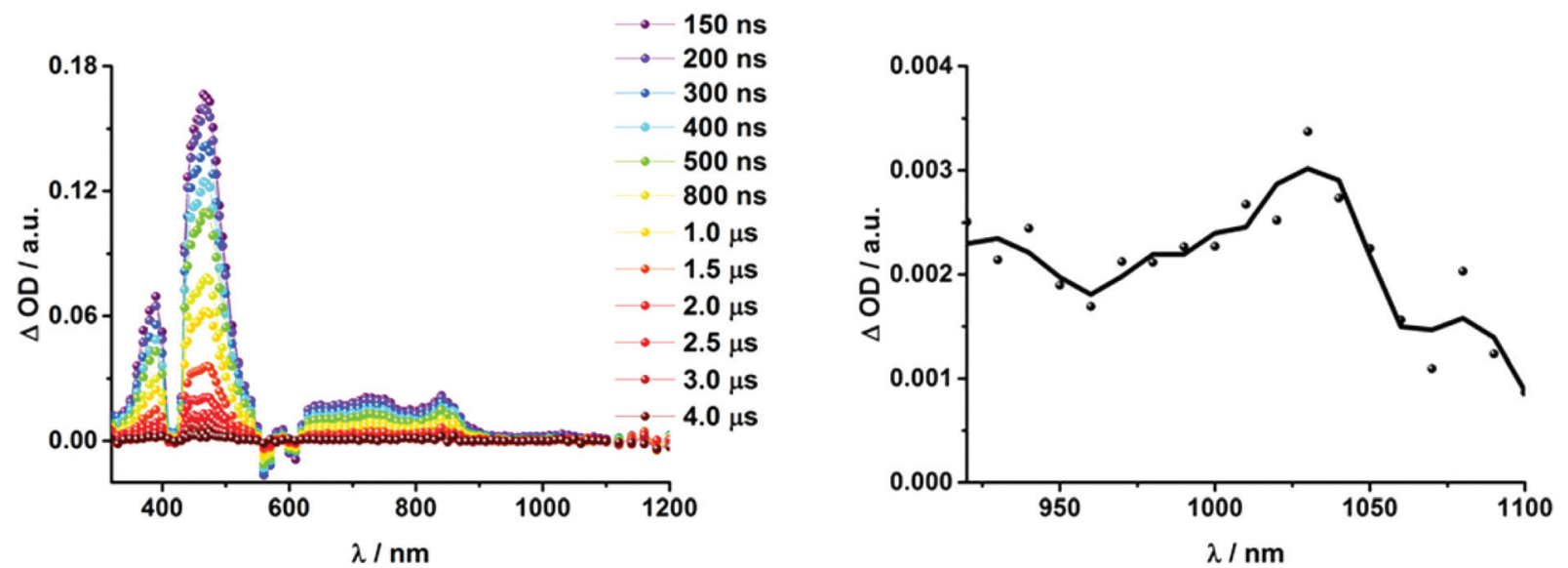

Fig. 10 Left: Transient absorption spectra (visible and near-infrared) observed upon ns flash photolysis $(532 \mathrm{~nm}, 10 \mathrm{~mJ})$ of $\mathrm{MgP}-\left[\mathrm{Cu}(\mathrm{phen})_{2}\right]^{+}-\mathrm{C}_{60}$ catenate 11 in THF with time delays between 150 ns and $4.0 \mu$ s at room temperature under aerobic conditions. Right: Transient absorption spectrum (near-infrared) observed upon ns flash photolysis $\left(532 \mathrm{~nm}\right.$ ) of $\mathrm{MgP}-\left[\mathrm{Cu}(\text { phen })_{2}\right]^{+}-\mathrm{C}_{60}$-catenate 11 in THF with a time delay of $150 \mathrm{~ns}$ at room temperature under aerobic conditions.
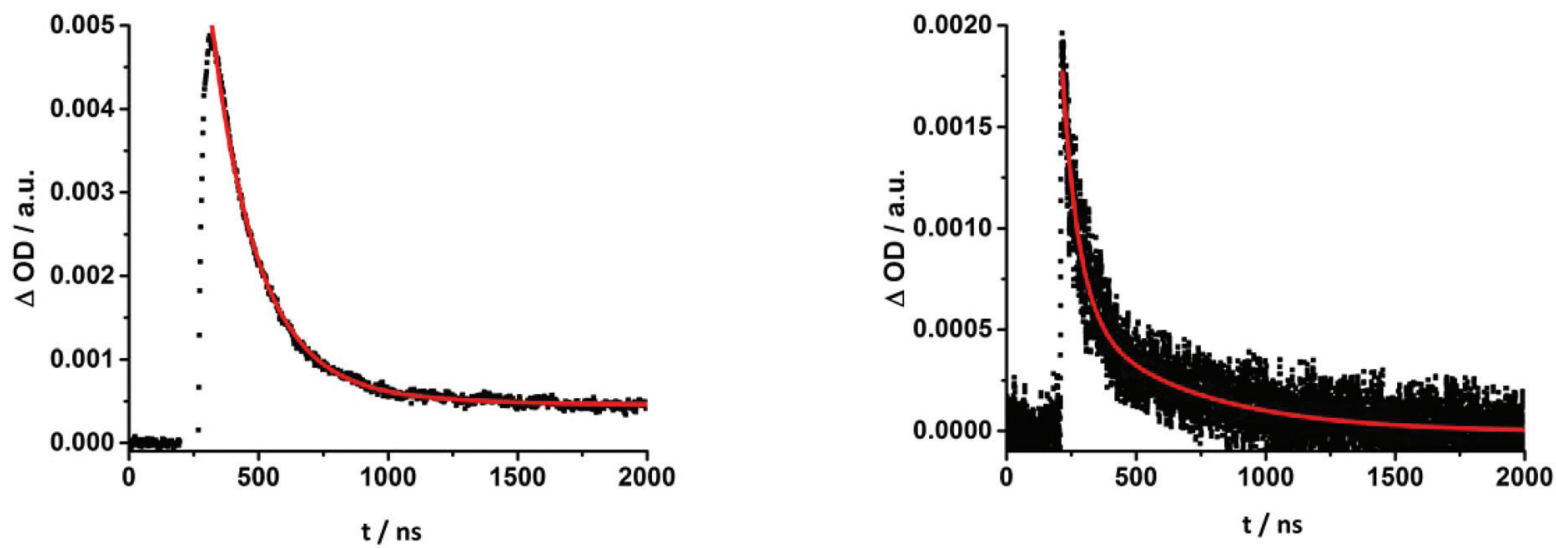

Fig. 11 Left: Time-absorption profile observed upon nanosecond flash photolysis $(355 \mathrm{~nm})$ of $\mathrm{MgP}-\left[\mathrm{Cu}(\mathrm{phen})_{2}\right]^{+}-\mathrm{C}_{60}$ catenate 11 in $\mathrm{THF}$ at $680 \mathrm{~nm}$ in THF saturated with molecular oxygen, monitoring back ET. Right: Time-absorption profile observed upon nanosecond flash photolysis $\left(355 \mathrm{~nm}\right.$ ) of $\mathrm{MgP}-\left[\mathrm{Cu}(\text { phen })_{2}\right]^{+}-\mathrm{C}_{60}$ catenate $11 \mathrm{in} \mathrm{THF}$ at $1030 \mathrm{~nm}$ under aerobic conditions, monitoring back ET. 


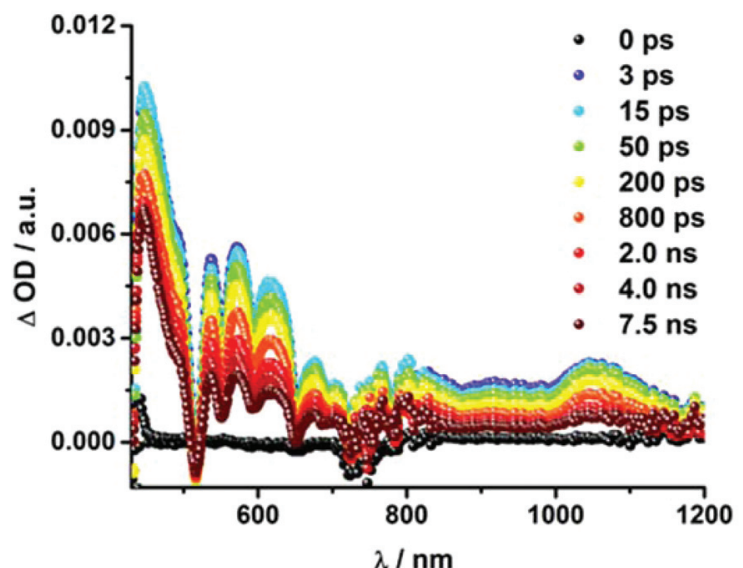

Fig. 12 Differential absorption spectra (visible and near-infrared) registered upon femtosecond flash photolysis (387 nm, $200 \mathrm{~nJ}$ ) of $\mathrm{H}_{2} \mathrm{P}-$ $\left[\mathrm{Cu}(\text { phen })_{2}\right]^{+}-\mathrm{C}_{60}$ catenate 12 in THF with time delays between 0 and $7.5 \mathrm{~ns}$ at room temperature.

$1035 \mathrm{~nm}$ decay follows a biexponential rate law with lifetimes of 60 and $700 \mathrm{~ns}$ in THF in the absence as well as the presence of oxygen. The shorter lifetime resembles that found for CSS in reference catenate $\mathbf{1 3}$ and is ascribed to the close $\mathrm{MgP}-$ $\left[\mathrm{Cu}(\text { phen })_{2}\right]^{2+}-\mathrm{C}_{60}{ }^{--}$CSS. The fact that the shorter lifetime seen for 11 (60 ns) is less than that of 13 (100 ns) indicates that there is an additional deactivation pathway for the close CSS in catenate 11 when $\mathrm{MgP}$ is present, namely a charge shift from $\mathrm{MgP}$ to the oxidized $\mathrm{Cu}$ ion. The longer lifetime of $700 \mathrm{~ns}$ observed with $\mathbf{1 1}$ matches the lifetime found for the one electron oxidized form of $\mathrm{MgP}$, and is assigned to the long distance $\mathrm{MgP}^{\cdot+}-\left[\mathrm{Cu}(\text { phen })_{2}\right]^{+}-\mathrm{C}_{60}{ }^{\cdot-}$ CSS. Clearly, back ET in catenate 11, although exergonic, is inhibited due to the spatial separation of the oxidized donor and the reduced acceptor and the fact that the process is in the Marcus inverted region.
From the transient absorption spectra of $\mathrm{H}_{2} \mathrm{P}-$ $\left[\mathrm{Cu}(\text { phen })_{2}\right]^{+}-\mathrm{C}_{60}$ catenate $\mathbf{1 2}$ a similar reaction pattern is derived. Excitation at $420 \mathrm{~nm}$ is followed by the immediate formation of the $\mathrm{H}_{2} \mathrm{P}$ singlet excited state with maxima at 450 , $540,570,620$, and $680 \mathrm{~nm}$ as well as a broad transient absorption between 1000-1150 $\mathrm{nm}$. These features are stable on the time scale of our experimental setup of 7.5 ns. Additionally, ground state bleaching at 420,520, 550, 590, and $650 \mathrm{~nm}$ is seen, corresponding to the Soret- and Q-band absorption of $\mathrm{H}_{2}$ P. Fig. 12 shows that upon excitation of 12 at $387 \mathrm{~nm}$ the transient absorption of the $\mathrm{C}_{60}$ singlet excited state is also observed in the region between 850 and $1000 \mathrm{~nm}$. However, assignment of CSS involving the one electron oxidized form of $\mathrm{H}_{2} \mathrm{P}$ at $680 \mathrm{~nm}$ and the one electron reduced form of $\mathrm{C}_{60}$ at $1035 \mathrm{~nm}$ is hampered in these femtosecond experiments by the much stronger $\mathrm{H}_{2} \mathrm{P}$ excited state features. In complementary nanosecond experiments absorption at $1035 \mathrm{~nm}$ is clearly observable upon excitation at $355 \mathrm{~nm}$ as well as $532 \mathrm{~nm}$ - Fig. 13. Taking a closer look at the kinetics of the $1035 \mathrm{~nm}$ decay in THF - Fig. 14 - lifetimes of 20 and $400 \mathrm{~ns}$ are derived. Similarly, the decay at $680 \mathrm{~nm}$ is fit with a lifetime of $400 \mathrm{~ns}$ in THF in oxygen-saturated solution. Analogously to catenate 11, the longer lifetime for $\mathbf{1 2}$ correlates with the distant $\mathrm{H}_{2} \mathrm{P}^{\cdot+}-\left[\mathrm{Cu}(\text { phen })_{2}\right]^{+}-\mathrm{C}_{60}{ }^{\cdot-}$ CSS, while the shorter lifetime is assigned to the close $\mathrm{H}_{2} \mathrm{P}-\left[\mathrm{Cu}(\text { phen })_{2}\right]^{2+}-\mathrm{C}_{60}{ }^{\cdot-}$ CSS.

Efficiency of ET. Transient absorption measurements have clearly proven that $\mathrm{MgP}-$ and $\mathrm{H}_{2} \mathrm{P}-\left[\mathrm{Cu}(\text { phen })_{2}\right]^{+}-\mathrm{C}_{60}$ catenates 11 and 12 undergo ET upon photoexcitation. Their $\mathrm{ZnP}$ analog 10 is known from our earlier work ${ }^{23}$ to form a long lived CSS. However, steady state experiments suggest that the efficiency for ET in these three porphyrin- $\mathrm{C}_{60}$ catenates is not the same. Redox potentials derived from electrochemical data imply a reduced driving force for the electron transfer in $\mathbf{1 2}$ and an enhanced driving force for $\mathbf{1 1}$ compared to $\mathbf{1 0}$ - Tables 1 and 4. Fluorescence quantum yields - Table 2 - underline this
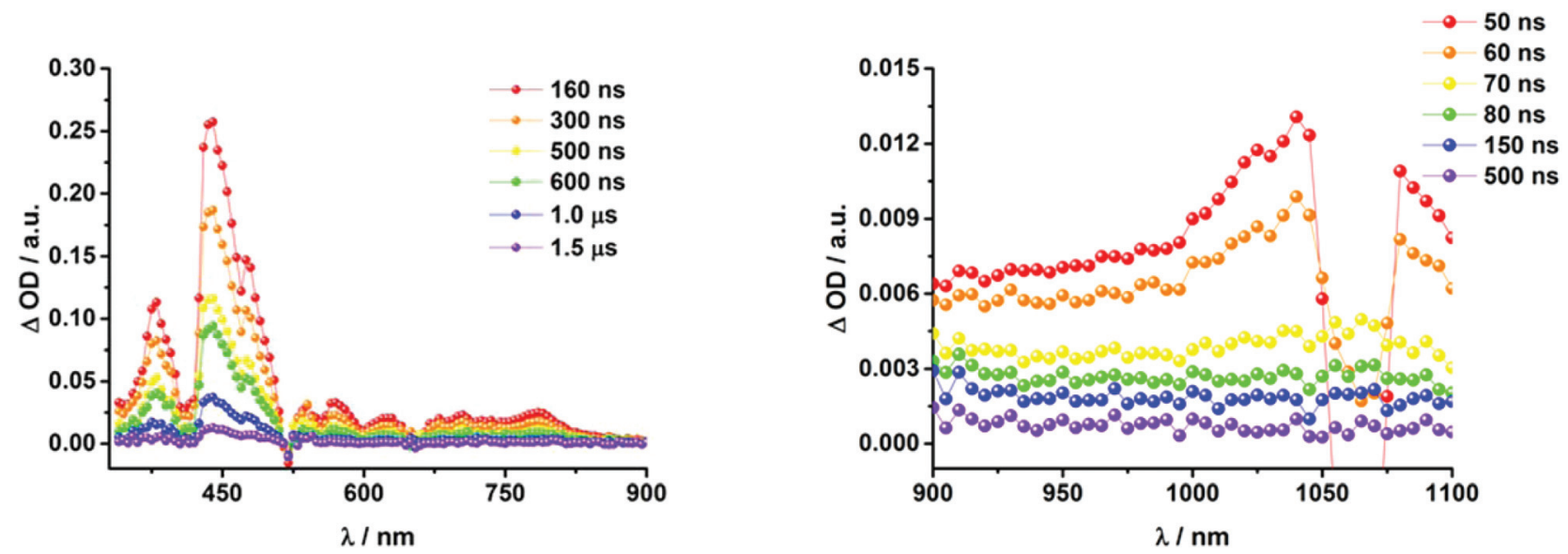

Fig. 13 Left: Differential absorption spectra (visible and near-infrared) registered upon femtosecond flash photolysis $(532 \mathrm{~nm}, 10 \mathrm{~mJ})$ of $\mathrm{H}_{2} \mathrm{P}-$ $\left[\mathrm{Cu}(\text { phen })_{2}\right]^{+}-\mathrm{C}_{60}$ catenate 12 in THF with time delays between 160 ns and $1.5 \mu$ s at room temperature. Right: Differential absorption spectra (near-infrared) registered upon femtosecond flash photolysis $\left(532 \mathrm{~nm}, 10 \mathrm{~mJ}\right.$ ) of $\mathrm{H}_{2} \mathrm{P}-\left[\mathrm{Cu}(\text { phen })_{2}\right]^{+}-\mathrm{C}_{60}$ catenate 12 in THF with time delays between 50 ns and 500 ns at room temperature. 

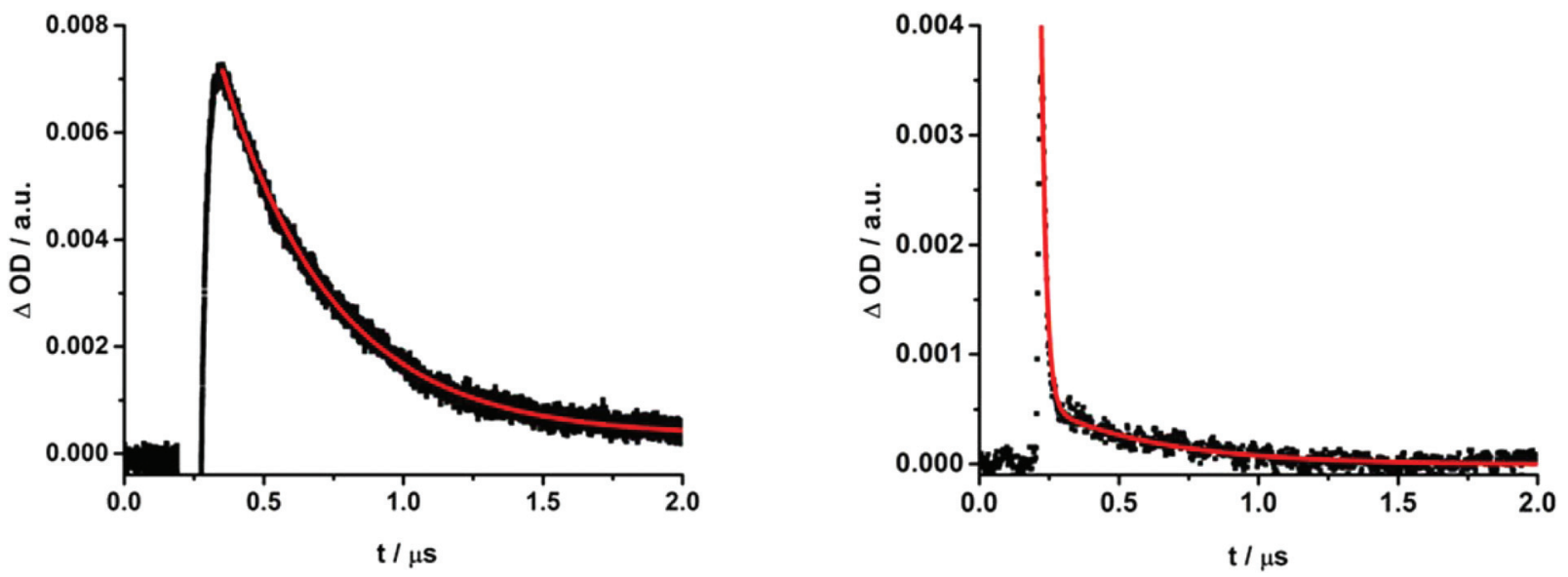

Fig. 14 Time-absorption profiles of the spectra in Fig. 13 at $690 \mathrm{~nm}$ (left) and $1035 \mathrm{~nm}$ (right), monitoring back ET.

Table 4 Charge separated state lifetimes and driving forces for ET of the porphyrin- $\mathrm{C}_{60}$ catenates

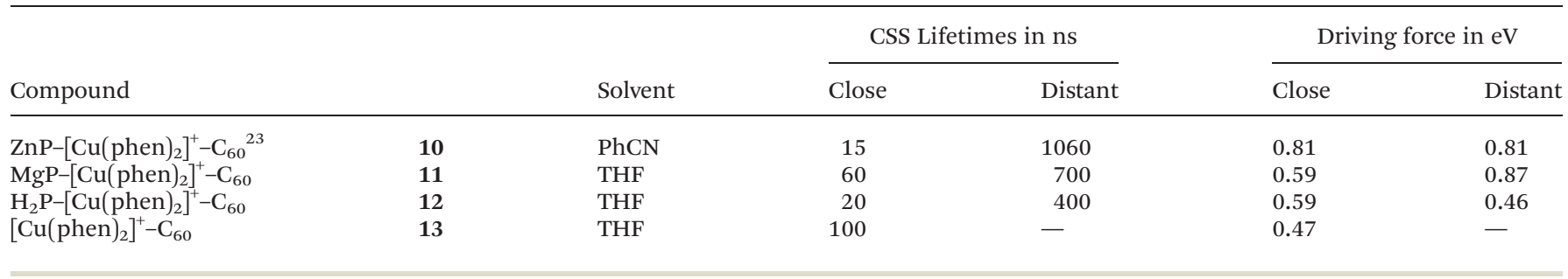

trend. In 12, the porphyrin fluorescence is only $30 \%$ quenched compared to that of the $\mathrm{H}_{2} \mathrm{P}$ reference $\mathbf{8}$, while in $\mathbf{1 1}$ the porphyrin fluorescence is over $60 \%$ lower than that of $\mathrm{MgP}$ reference 7; ZnP catenate 10 shows fluorescence quenching of $75 \%$ compared to a ZnP reference. ${ }^{23}$ Furthermore, the quantum yields for singlet oxygen formation $\Phi_{\Delta}$ is almost $50 \%$ lower for 12 compared to 8, whereas for $\mathrm{MgP}$ catenate $11 \Phi_{\Delta}$ is more than $60 \%$ lower than that of $\mathrm{MgP}$ reference 7.

To find out more about the efficiency of the ET process, ns transient absorption was carried out with catenates 10, 11, and 12 under exactly the same conditions and the $\mathrm{C}_{60}$ radical anion absorption in the NIR region for each catenate was compared with respect to its intensity at the maximum - Fig. 15. In line with the predictions made from the steady state experiments, 10 clearly shows the strongest $\mathrm{C}_{60}$ anion signature absorption. Catenates $\mathbf{1 1}$ and 12 exhibited considerably weaker $\mathrm{C}_{60}{ }^{--}$absorptions, namely $54 \%$ and $74 \%$ relative to 10 , which is in agreement with the weaker quenched porphyrin fluorescence. Those findings can be rationalized taking into account the driving forces for the ETs in the different catenates (Table 4).

The largest driving force to form the close CSS was found for $10(0.81 \mathrm{eV})$, compared to $0.59 \mathrm{eV}$ for 11 and 12 (for further discussion, see summary and conclusions).

Table 4 summarizes the CSS lifetimes of the investigated catenates 11, 12, and $\mathbf{1 3}$ as well as $\mathrm{ZnP}-\left[\mathrm{Cu}(\text { phen })_{2}\right]^{+}-\mathrm{C}_{60} \mathbf{1 0}$,

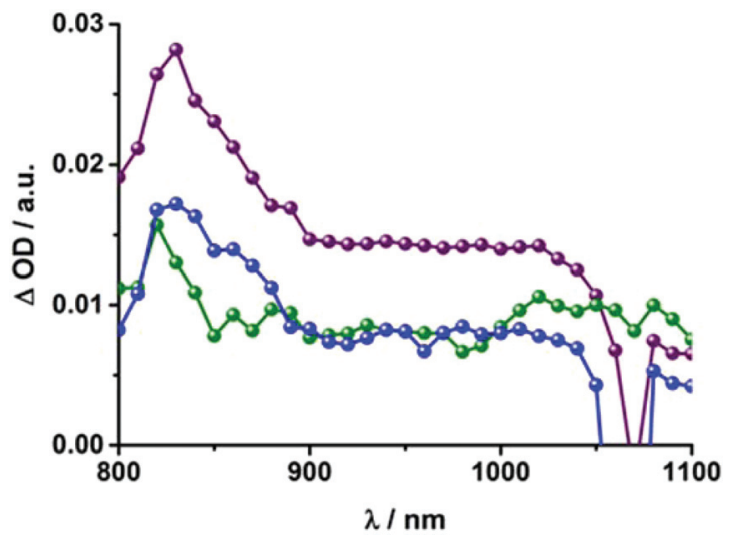

Fig. 15 Differential absorption spectra (near-infrared) registered upon nanosecond flash photolysis $(532 \mathrm{~nm}, 10 \mathrm{~mJ}$ ) of catenates 10 (purple), 11 (blue), and 12 (olive) in THF at room temperature under aerobic conditions.

which we previously reported. ${ }^{23}$ When comparing the three $\mathrm{P}-\left[\mathrm{Cu}(\text { phen })_{2}\right]^{+}-\mathrm{C}_{60}$ catenates, the influence of the metalloporphyrin on the charge separated states becomes evident. Catenate $\mathbf{1 1}$ reveals the longest lifetime for the close $\mathrm{P}-\left[\mathrm{Cu}(\text { phen })_{2}\right]^{2+}-\mathrm{C}_{60}{ }^{--}$charge separated state, while its $\mathrm{ZnP}$ analog 10 exhibits the longest lifetime for the long distance $\mathrm{P}^{\cdot+}-\left[\mathrm{Cu}(\text { phen })_{2}\right]^{+}-\mathrm{C}_{60} \cdot-\mathrm{CSS}$. 


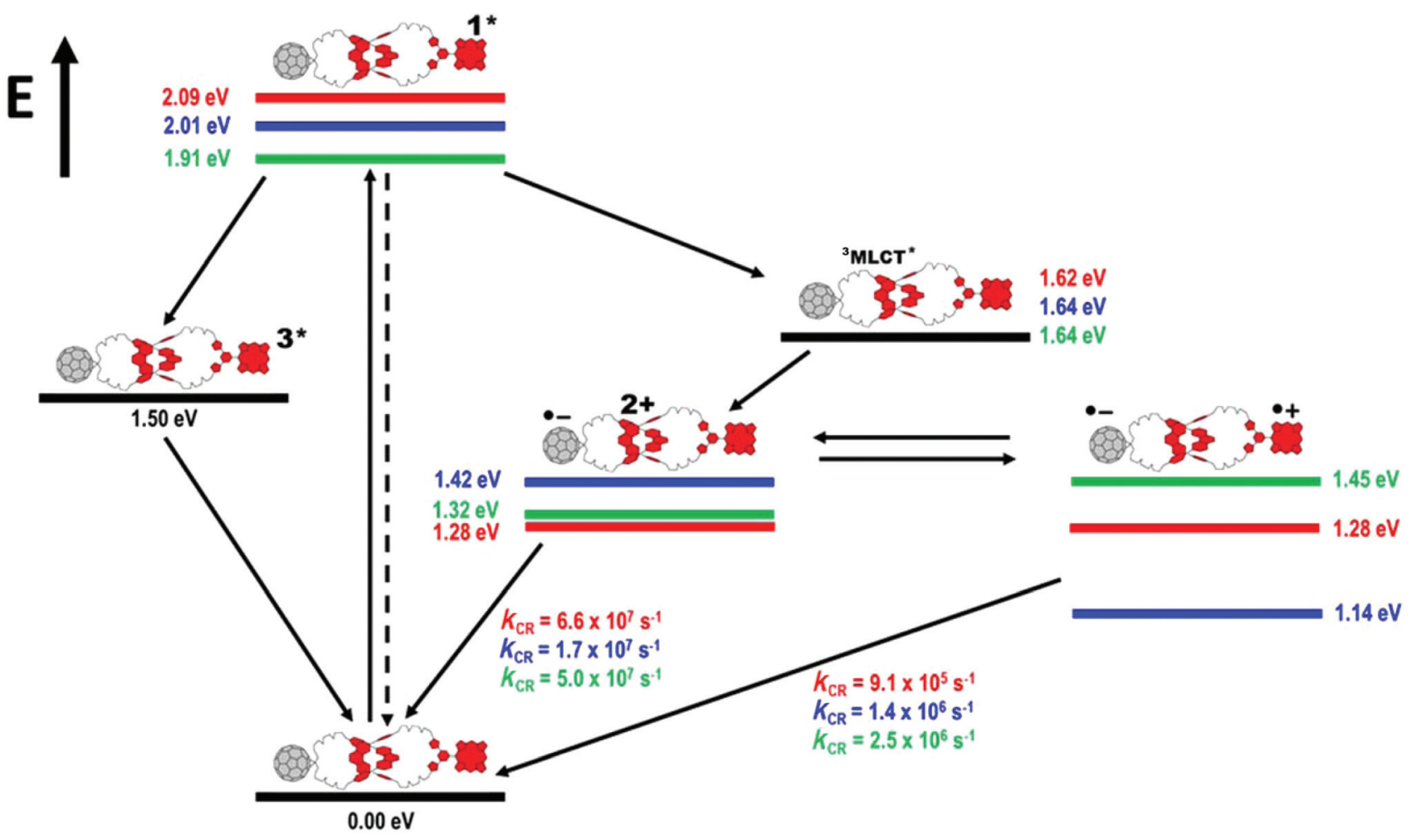

Fig. 16 Schematic energy level diagrams, proposed decay pathways and rate constants for $\mathrm{P}-\mathrm{Cu}^{+}-\mathrm{C}_{60}$ catenates $10^{23}$ (red numbers), 11 (blue numbers), and 12 (green numbers) upon excitation at $420 \mathrm{~nm}$. $k_{\mathrm{CR}}=$ charge recombination rate.

\section{Summary and conclusions}

In this work, we have demonstrated that a sequence of EnT and ET processes take place upon photoexcitation of MgP catenane 11 and $\mathrm{H}_{2} \mathrm{P}$ catenate 12. In particular, upon $420 \mathrm{~nm}$ excitation of the porphyrins, their singlet excited states are formed with energies of about $2 \mathrm{eV}$ relative to the ground state (see Table 2 and Fig. 16). From these singlet excited states, deactivation processes occur via the energetically lower lying triplet excited states of either the porphyrin $(\sim 1.5 \mathrm{eV})$ or the copperphenanthroline complex $(\sim 1.6 \mathrm{eV})$. The porphyrin triplet excited state decays directly back to the ground state, while ET evolves from the $\left[\mathrm{Cu}(\text { phen })_{2}\right]^{+}$triplet excited MLCT state. In both catenates, the close $\mathrm{P}-\left[\mathrm{Cu}(\text { phen })_{2}\right]^{2+}-\mathrm{C}_{60}{ }^{\cdot-}$ CSS is first formed with an oxidized $\mathrm{Cu}$ ion. Subsequent charge shift yields the distant

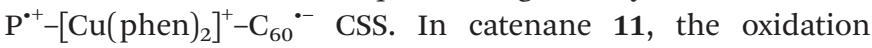
potential for $\mathrm{MgP}$ is lower than that of $\left[\mathrm{Cu}(\text { phen })_{2}\right]$, which leads to a lower lying distant $\mathrm{MgP}^{\cdot+}-\left[\mathrm{Cu}(\text { phen })_{2}\right]^{+}-\mathrm{C}_{60}{ }^{--}$CSS $(1.14 \mathrm{eV})$, compared to the close CSS $(1.42 \mathrm{eV})$. In turn, the charge shift is thermodynamically downhill. Evidence for the involvement of both states comes from the back ET dynamics.

The decay kinetics of the $\mathrm{C}_{60}$ radical anion in $\mathbf{1 1}$ at $1030 \mathrm{~nm}$ (Fig. 11) requires a biexponential fit, yielding lifetimes of $60 \mathrm{~ns}$ $\left(k=5.0 \times 10^{7} \mathrm{~s}^{-1}\right)$ and $700 \mathrm{~ns}\left(k=2.5 \times 10^{6} \mathrm{~s}^{-1}\right)$. The faster decay is assigned to back ET in the $\mathrm{MgP}-\left[\mathrm{Cu}(\text { phen })_{2}\right]^{2+}-\mathrm{C}_{60}{ }^{\cdot-}$ CSS, since the dynamics resemble those seen in reference catenate 13. The longer lifetime matches the lifetimes determined for the single oxidized $\mathrm{MgP}$ and is, thus, assigned to back
ET of the $\mathrm{MgP}^{+}-\left[\mathrm{Cu}(\text { phen })_{2}\right]^{+}-\mathrm{C}_{60}{ }^{--}$CSS. For catenane 12, the redox potentials - Table 2 - suggest that the close CSS is energetically lower than the distant CSS, namely $1.32 \mathrm{eV}$ compared to $1.45 \mathrm{eV}$. In spite of that, the charge shift to afford the distant $\mathrm{H}_{2} \mathrm{P}^{\cdot+}-\left[\mathrm{Cu}(\text { phen })_{2}\right]^{+}-\mathrm{C}_{60}{ }^{--}$CSS seems to take place. Kinetic evidence comes from the biexponential decay of the $\mathrm{C}_{60}$ radical anion fingerprint - Fig. 14. Nevertheless, the pre-exponential factors for the short lifetime of $20 \mathrm{~ns}$ for the close CSS is $10^{6}$ times larger than for the longer lifetime of $400 \mathrm{~ns}$ for the distant CSS. This gives rise to the conclusion that only a small portion of $\mathrm{H}_{2} \mathrm{P}-\left[\mathrm{Cu}(\text { phen })_{2}\right]^{+}-$ $\mathrm{C}_{60}$ catenanes 12 undergoes charge shift to yield the distant CSS.

Fig. 16 schematically depicts the sequence of photoinduced processes and the energy levels determined from electrochemical and spectroscopic investigations together with the back ET dynamics from our newly investigated catenanes $\mathbf{1 1}$ and $\mathbf{1 2}$ as well as the previously studied catenate $\mathbf{1 0}^{23}$ At first glance, compared to the previously studied $\mathrm{ZnP}-\left[\mathrm{Cu}(\text { phen })_{2}\right]^{+}-\mathrm{C}_{60}$ catenane $10,{ }^{23}$ in which the close and distant CSS appear to be isoenergetic, faster back ET was observed in both of the newly studied systems. $\mathrm{H}_{2} \mathrm{P}-\left[\mathrm{Cu}(\text { phen })_{2}\right]^{+}-\mathrm{C}_{60}$ catenane 12 has the shortest CSS lifetime (400 ns) of the three structurally similar catenated materials, which can be rationalized by the higher oxidation potential of $\mathrm{H}_{2} \mathrm{P}$ and, in turn, decreased driving force for electron (charge) transfer. On the other hand, the relatively low oxidation potentials of MgP suggest an increased driving force for electron (charge) transfer. 
A closer look at the ET driving forces reveals, however, that the differences are more distinct. For example, the driving force to form the close CSS in $\mathbf{1 1}$ and $\mathbf{1 2}$ are identical, $0.59 \mathrm{eV}$, and considerably smaller than the $0.81 \mathrm{eV}$ seen for $1 \mathbf{1 0}^{23}$ Considering that $\mathrm{H}_{2} \mathrm{P}$ in 12 is harder to oxidize (0.38 V; Table 1) than $\mathrm{ZnP}$ in 10 and $\mathrm{MgP}$ in 11, and that 12 also features the lowest singlet excited state energy (1.91 eV; Table 2) among these three, the ET driving force is nonetheless reduced in catenate 12. Although MgP is more susceptible towards oxidation than $\mathrm{H}_{2} \mathrm{P}$ and $\mathrm{ZnP}, 11$ does not possess the largest driving force, since its singlet excited state energy is lower than that for 10. Moreover, the close $\mathrm{MgP}-\left[\mathrm{Cu}(\text { phen })_{2}\right]^{2+}-\mathrm{C}_{60}{ }^{--} \mathrm{CSS}$ has a higher energy than $\mathrm{ZnP}-\left[\mathrm{Cu}(\text { phen })_{2}\right]^{2+}-\mathrm{C}_{60}{ }^{--}$and $\mathrm{H}_{2} \mathrm{P}-$ $\left[\mathrm{Cu}(\text { phen })_{2}\right]^{2+}-\mathrm{C}_{60}{ }^{--}$. As a matter of fact, the latter numbers are in sound agreement with the efficiency results in terms of ET to afford the close CSS, namely $\mathbf{1 0}>\mathbf{1 2}>\mathbf{1 1}$. The energy levels for the distant CSS give a slightly different picture. In 12, the charge shift is very unlikely to occur, since the distant CSS is of higher energy $(1.45 \mathrm{eV})$ than the close CSS $(1.32 \mathrm{eV})$. This is also reflected in the transient absorption spectra and the corresponding kinetics - see Fig. 13 and 14. Here, much higher intensities evolve for the close CSS with its 20 ns lifetimes than for the distant CSS. In 12, the latter is highest in energy relative to $\mathbf{1 0}$ and $\mathbf{1 1}$ and gives rise to the shortest lifetime, namely $400 \mathrm{~ns}$. In 11, the charge shift is downhill with a driving force of $0.87 \mathrm{eV}$. Finally, in the case of 10, in which both close and distant CSS have the same energy $(1.28 \mathrm{eV}){ }^{23}$ exhibits a comparable driving force of $0.81 \mathrm{eV}$. Still, ET occurs most efficiently in $\mathbf{1 0}$ despite the slowest charge recombination rate.

Based on the aforementioned considerations, we analyzed the dynamics for all charge separation, charge shift and charge recombination processes for the close and distant CSS, respectively, with the Marcus formalism, ${ }^{30}$ from which we derived reorganization energies of $0.57 \mathrm{eV}$ for the close CSS and $0.67 \mathrm{eV}$ for the distant CSS, respectively.

From those results we conclude that the initial EnT from the porphyrin to the $\left[\mathrm{Cu}(\text { phen })_{2}\right]^{+}$is the efficiency determining step. ZnP in 10 exhibits the highest lying singlet excited state $(2.09 \mathrm{eV})$, the strongest fluorescence quenching of $\sim 75 \%$, and the shortest lived singlet excited state ( 0.5 ns; see Table 2). In stark contrast, in 11 and 12 the $\mathrm{MgP}$ and $\mathrm{H}_{2} \mathrm{P}$ fluorescence is only quenched about $60 \%$ and $30 \%$, respectively. Thus, EnT from the $\mathrm{ZnP}$ singlet excited state to $\left[\mathrm{Cu}(\text { phen })_{2}\right]^{+}(1.6 \mathrm{eV})$ is more efficient than from the $\mathrm{MgP}$ singlet excited state $(2.01 \mathrm{eV})$ and the $\mathrm{H}_{2} \mathrm{P}$ singlet excited state $(1.91 \mathrm{eV})$. Consequently, 10 undergoes a more efficient subsequent ET. Additionally, the initial ET to afford the close CSS seems to play an important role. The driving forces determined for this process reflect the tendency seen for the efficiency of the ET process and also the lifetimes for the distant CSS, namely that ET in $\mathbf{1 0}$ is most efficient and back ET is slowest $\left(9.1 \times 10^{5} \mathrm{~s}^{-1}\right) .{ }^{23}$

In summary, it has been shown that replacing $\mathrm{ZnP}$ with $\mathrm{MgP}$ or $\mathrm{H}_{2} \mathrm{P}$ in $\left[\mathrm{Cu}(\text { phen })_{2}\right]^{2+}-\mathrm{C}_{60}$ catenates does not enhance ET processes or give longer lived CSS. Nevertheless, we demonstrated that $\mathrm{MgP}-\left[\mathrm{Cu}(\text { phen })_{2}\right]^{+}-\mathrm{C}_{60} \quad \mathbf{1 1}$ as well as $\mathrm{MgP}-$ $\left[\mathrm{Cu}(\text { phen })_{2}\right]^{+}-\mathrm{C}_{60} \mathbf{1 2}$ undergo EnT as well as ET followed by a charge shift to form the long lived radical ion pair $\mathrm{P}^{{ }^{+}}$$\left[\mathrm{Cu}(\text { phen })_{2}\right]^{+}-\mathrm{C}_{60}{ }^{--}$with lifetimes of hundreds of nanoseconds. The comprehensive photophysical and electrochemical characterization of the catenates and their references yielded a useful set of thermodynamic and kinetic data. Thus, critical comparison with the previously studied $\mathrm{ZnP}$ analog provided new insights into the effects of the porphyrin metal center (or the lack of it) on ET dynamics in mechanically interlocked artificial photosynthetic model systems.

\section{Experimental section}

\section{General information and materials}

NMR spectra were obtained on either a Bruker AVANCE 400 (400 MHz) or an AVANCE $800(800 \mathrm{MHz})$ spectrometer using deuterated solvents as the lock. The spectra were collected at $25{ }^{\circ} \mathrm{C}$, and chemical shifts $(\delta, \mathrm{ppm})$ were referenced to residual solvent peak. In the assignments, the chemical shift (in ppm) is given first, followed, in parentheses, by multiplicity ( $\mathrm{s}$, singlet; d, doublet; $\mathrm{t}$, triplet; $\mathrm{m}$, multiplet; br, broad), the number of protons implied and finally the assignment. In the ${ }^{1} \mathrm{H}$ NMR assignment $(\delta), \mathrm{H}_{\mathrm{o}}$ and $\mathrm{H}_{\mathrm{m}}$ refer to the hydrogen atoms at the ortho and meta positions, respectively, of the phenyl ring attached to the phenanthroline ring system, whose hydrogen atoms are numbered $\mathrm{H}_{3,8}, \mathrm{H}_{4,7}$ and $\mathrm{H}_{5,6}$, respectively. $\mathrm{ZnP}, \mathrm{MgP}$ and $\mathrm{H}_{2} \mathrm{P}$ are used as abbreviations for zinc(II)porphyrin, magnesium(II)porphyrin and free-base porphyrin, respectively. MALDI-TOF mass spectra were recorded in a Bruker Omni FLEX MALDI-TOF MS spectrometer. This instrument was operated at an accelerating potential of $20 \mathrm{kV}$ in linear mode. The mass spectra represent an average over 256 consecutive laser shots. The mass scale was calibrated using the matrix peaks and the calibration software available from Bruker OmniFLEX. Mentioned $\mathrm{m} / \mathrm{z}$ values correspond to monoisotopic masses. The compound solutions $\left(10^{-3} \mathrm{~mol} \mathrm{~L}^{-1}\right)$ were prepared in THF. The matrix, $\alpha$-cyano-4-hydroxycinnamic acid (CCA), was purchased from Aldrich and used without further purification, while 1,4 benzoquinone (BQ), also from Aldrich, was recrystallized from ethanol before use. BQ was used as matrix for magnesium containing compounds, whereas CCA was employed for all other compounds. The appropriate matrix was dissolved $\left(10 \mathrm{~g} \mathrm{~L}^{-1}\right)$ in a solvent mixture composed of $\mathrm{H}_{2} \mathrm{O}-\mathrm{CH}_{3} \mathrm{CN}-\mathrm{TFA}(25 / 75 / 1, \mathrm{v} / \mathrm{v})$. Two microliters of compound solution was mixed with $10 \mu \mathrm{L}$ of matrix solution. The final solution was deposited onto the sample target and allowed to dry in air. All chemicals were purchased from Sigma-Aldrich and Alfa Aesar and used without further purification. For moisture-sensitive reactions, solvents were freshly distilled. Methylene chloride $\left(\mathrm{CH}_{2} \mathrm{Cl}_{2}\right)$ and acetonitrile $\left(\mathrm{CH}_{3} \mathrm{CN}\right)$ were dried over calcium hydride while tetrahydrofuran (THF) was dried using sodium/benzophenone. Anhydrous dimethylformamide (DMF) was used as received. All syntheses were carried out using Schlenk line techniques. Moisture-sensitive liquids were transferred by cannula or syringe. The progress of the reactions was monitored by thin- 
layer chromatography (TLC) whenever possible. TLC was performed using precoated glass plates (silica gel 60, $0.25 \mathrm{~mm}$ thickness) containing a $254 \mathrm{~nm}$ fluorescent indicator. Column chromatography was carried out using Merck silica gel 60 (0.063-0.200 $\mathrm{mm}$ ) and neutral alumina (Brockmann I, activated, 150 mesh, $58 \AA$ ).

\section{Synthesis}

Building blocks 1, 2 and 3 as well as porphyrin derivatives 6 and $\mathbf{8}$ were prepared according to our previous published reports. Porphyrin 7 and the fullerene model compound $\mathbf{1 6}$ were afforded as described in the literature. ${ }^{23}$ All of the [2]catenates reported were synthesized from the suitable precursors following the general procedure for preparation of catenates described in our previous work. ${ }^{20-25,45,46}$

[2]Catenate $\mathbf{1 0}$ was synthesized from precursor $\mathbf{4}$ and porphyrin 6. Final purification was achieved by column chromatography $\left(\mathrm{SiO}_{2}\right)$ using a gradient of $\mathrm{CH}_{2} \mathrm{Cl}_{2}-\mathrm{CH}_{3} \mathrm{OH}(99: 1 \mathrm{v} / \mathrm{v})$ as eluent, affording $\mathbf{1 0}$ as a greenish purple solid $(0.078 \mathrm{~g}, 57 \%$ yield). ${ }^{1} \mathrm{H}$ NMR ( $\left.\mathrm{CD}_{3} \mathrm{CN}\right), \delta$ ppm: $8.98\left(\mathrm{~s}, 1 \mathrm{H}, H_{\mathrm{a}}\right) ; 8.77(\mathrm{~d}, 4 \mathrm{H}$, pyrrolic protons); 8.69 (d, 2H, pyrrolic protons); 8.57 (d, $2 \mathrm{H}$, pyrrolic protons); 8.45 (dd, $4 \mathrm{H}, H_{4^{\prime}}, H_{7^{\prime}}, H_{4}$, and $\left.H_{7}\right) ; 8.11$ (s, $\left.2 \mathrm{H}, H_{\mathrm{b}}\right) ; 7.85$ (s, 6H, $H_{\mathrm{c}}$ on $\mathrm{ZnP}$ tert-butylphenyl groups); 7.81 (s, $\left.2 \mathrm{H}, H_{\mathrm{d}}\right) ; 7.80\left(\mathrm{~s}, 2 \mathrm{H}, H_{5^{\prime}}\right.$ and $\left.H_{6^{\prime}}\right) ; 7.79\left(\mathrm{~s}, 2 \mathrm{H}, H_{5}\right.$ and $\left.H_{6}\right)$; $7.64\left(\mathrm{~d}, 2 \mathrm{H}, H_{3^{\prime}}\right.$ and $\left.H_{8^{\prime}}\right) ; 7.63\left(\mathrm{~s}, 3 \mathrm{H}, H_{\mathrm{e}}\right.$ on ZnP-tert-butylphenyl group); 7.36 (d, $2 \mathrm{H}, H_{3}$ and $\left.H_{8}\right) ; 7.07$ (d, $\left.4 \mathrm{H}, H_{\mathrm{o}^{\prime}}\right) ; 6.74$ (d, $\left.4 \mathrm{H}, H_{\mathrm{o}}\right) ; 5.82\left(\mathrm{~d}, 4 \mathrm{H}, H_{\mathrm{m}^{\prime}}\right) ; 5.67$ (d, $\left.4 \mathrm{H}, H_{\mathrm{m}}\right) ; 5.04\left(\mathrm{~s}, 4 \mathrm{H}, H_{\mathrm{f}}\right)$; $4.69\left(\mathrm{~s}, 4 \mathrm{H}, H_{\mathrm{g}}\right) ; 4.80-3.00$ (m, oligo(ethylene glycol) linker); 1.54 (s, 54H, tertbutyl $\mathrm{CH}_{3}$ groups). MALDI-TOF: $\mathrm{m} / \mathrm{z}$ found $3216.1205\left[\mathrm{M}-\mathrm{PF}_{6}\right]^{+}$, calcd 3216.0098 for $\mathrm{C}_{207} \mathrm{H}_{152} \mathrm{~N}_{14} \mathrm{O}_{16} \mathrm{ZnCu}$.

[2]Catenate 11 was synthesized from precursor 4 and porphyrin 7. Final purification was achieved by column chromatography $\left(\mathrm{SiO}_{2}\right)$ using a gradient of $\mathrm{CH}_{2} \mathrm{Cl}_{2}-\mathrm{CH}_{3} \mathrm{OH}(99: 1 \mathrm{v} / \mathrm{v})$ as eluent, affording 11 as a greenish purple solid (0.072 g, 55\% yield). ${ }^{1} \mathrm{H}$ NMR ( $\left.\mathrm{CD}_{3} \mathrm{CN}\right), \delta$ ppm: $8.95\left(\mathrm{~s}, 1 \mathrm{H}, H_{\mathrm{a}}\right) ; 8.70(\mathrm{~d}, 4 \mathrm{H}$, pyrrolic protons); 8.62 (d, $2 \mathrm{H}$, pyrrolic protons); 8.56 (d, $2 \mathrm{H}$, pyrrolic protons); 8.46 (dd, $4 \mathrm{H}, H_{4^{\prime}}, H_{7^{\prime}}, H_{4}$, and $\left.H_{7}\right) ; 8.14$ (s, $\left.2 \mathrm{H}, H_{\mathrm{b}}\right) ; 7.83\left(\mathrm{~s}, 6 \mathrm{H}, H_{\mathrm{c}}\right.$ on MgP tert-butylphenyl groups); 7.80 $\left(\mathrm{s}, 2 \mathrm{H}, H_{\mathrm{d}}\right) ; 7.78\left(\mathrm{~s}, 2 \mathrm{H}, H_{5^{\prime}}\right.$ and $\left.H_{6^{\prime}}\right) ; 7.76\left(\mathrm{~s}, 2 \mathrm{H}, H_{5}\right.$ and $\left.H_{6}\right)$; $7.66\left(\mathrm{~d}, 2 \mathrm{H}, H_{3^{\prime}}\right.$ and $\left.H_{8^{\prime}}\right) ; 7.61\left(\mathrm{~s}, 3 \mathrm{H}, H_{\mathrm{e}}\right.$ on MgP-tert-butylphenyl group); 7.37 (d, 2H, $H_{3}$ and $\left.H_{8}\right) ; 7.06\left(\mathrm{~d}, 4 \mathrm{H}, H_{\mathrm{o}^{\prime}}\right) ; 6.75$ $\left(\mathrm{d}, 4 \mathrm{H}, H_{\mathrm{o}}\right) ; 5.84\left(\mathrm{~d}, 4 \mathrm{H}, H_{\mathrm{m}^{\prime}}\right) ; 5.69\left(\mathrm{~d}, 4 \mathrm{H}, H_{\mathrm{m}}\right) ; 5.03\left(\mathrm{~s}, 4 \mathrm{H}, H_{\mathrm{f}}\right) ;$ $4.70\left(\mathrm{~s}, 4 \mathrm{H}, H_{\mathrm{g}}\right) ; 4.80-3.00$ (m, oligo(ethylene glycol) linker); 1.59 (s, $54 \mathrm{H}$, tertbutyl $\mathrm{CH}_{3}$ groups). MALDI-TOF: $\mathrm{m} / \mathrm{z}$ found $3176.2091\left[\mathrm{M}-\mathrm{PF}_{6}\right]^{+}$, calcd 3176.0657 for $\mathrm{C}_{207} \mathrm{H}_{152} \mathrm{~N}_{14} \mathrm{O}_{16} \mathrm{MgCu}$.

[2]Catenate 12 was synthesized from precursor 4 and porphyrin 8. Final purification was achieved by column chromatography $\left(\mathrm{SiO}_{2}\right)$ using a gradient of $\mathrm{CH}_{2} \mathrm{Cl}_{2}-\mathrm{CH}_{3} \mathrm{OH}(98: 2 \mathrm{v} / \mathrm{v})$ as eluent, affording 12 as a purple solid ( $0.075 \mathrm{~g}, 58 \%$ yield). ${ }^{1} \mathrm{H}$ NMR ( $\left.\mathrm{CD}_{3} \mathrm{CN}\right), \delta$ ppm: $8.97\left(\mathrm{~s}, 1 \mathrm{H}, H_{\mathrm{a}}\right) ; 8.78(\mathrm{~d}, 4 \mathrm{H}$, pyrrolic protons); 8.73 (d, $2 \mathrm{H}$, pyrrolic protons); 8.68 (d, $2 \mathrm{H}$, pyrrolic protons); 8.48 (dd, $4 \mathrm{H}, H_{4^{\prime}}, H_{7^{\prime}}, H_{4}$, and $\left.H_{7}\right) ; 8.15$ (s, $2 \mathrm{H}, H_{\mathrm{b}}$ ); $7.89\left(\mathrm{~s}, 6 \mathrm{H}, H_{\mathrm{c}}\right.$ on $\mathrm{H}_{2} \mathrm{P}$ tert-butylphenyl groups); $7.83(\mathrm{~s}, 2 \mathrm{H}$, $\left.H_{\mathrm{d}}\right) ; 7.77\left(\mathrm{~s}, 2 \mathrm{H}, H_{5^{\prime}}\right.$ and $\left.H_{6^{\prime}}\right) ; 7.74\left(\mathrm{~s}, 2 \mathrm{H}, H_{5}\right.$ and $\left.H_{6}\right) ; 7.69(\mathrm{~d}$,
$2 \mathrm{H}, H_{3^{\prime}}$ and $\left.H_{8^{\prime}}\right) ; 7.65\left(\mathrm{~s}, 3 \mathrm{H}, H_{\mathrm{e}}\right.$ on $\mathrm{H}_{2} \mathrm{P}$-tert-butylphenyl group); $7.38\left(\mathrm{~d}, 2 \mathrm{H}, H_{3}\right.$ and $\left.H_{8}\right) ; 7.05\left(\mathrm{~d}, 4 \mathrm{H}, H_{\mathrm{o}^{\prime}}\right) ; 6.72(\mathrm{~d}, 4 \mathrm{H}$, $\left.H_{\mathrm{o}}\right) ; 5.88\left(\mathrm{~d}, 4 \mathrm{H}, H_{\mathrm{m}^{\prime}}\right) ; 5.70\left(\mathrm{~d}, 4 \mathrm{H}, H_{\mathrm{m}}\right) ; 5.03\left(\mathrm{~s}, 4 \mathrm{H}, H_{\mathrm{f}}\right) ; 4.73(\mathrm{~s}$, $\left.4 \mathrm{H}, H_{\mathrm{g}}\right)$; 4.80-3.00 (m, oligo(ethylene glycol) linker); 1.65 (s, $54 \mathrm{H}$, tertbutyl $\mathrm{CH}_{3}$ groups). MALDI-TOF: $\mathrm{m} / \mathrm{z}$ found 3154.5001 $\left[\mathrm{M}-\mathrm{PF}_{6}\right]^{+}$, calcd 3154.0963 for $\mathrm{C}_{207} \mathrm{H}_{154} \mathrm{~N}_{14} \mathrm{O}_{16} \mathrm{Cu}$.

[2]Catenate 13. This model compound was synthesized from precursor 4 and compound 9. Final purification was achieved by column chromatography $\left(\mathrm{SiO}_{2}\right)$ using a gradient of $\mathrm{CH}_{2} \mathrm{Cl}_{2}-\mathrm{CH}_{3} \mathrm{OH}(99: 1 \mathrm{v} / \mathrm{v})$ as eluent, affording 13 as a brown solid (0.071 g, 75\% yield). ${ }^{1} \mathrm{H}$ NMR $\left(\mathrm{CDCl}_{3}\right), \delta \mathrm{ppm:} 8.88(\mathrm{~s}, 1 \mathrm{H}$, $\left.H_{\mathrm{a}}\right) ; 8.42(\mathrm{dd}, 4 \mathrm{H}$, pyrrolic protons); 8.73 (d, 2H, pyrrolic protons); 8.68 (d, $2 \mathrm{H}$, pyrrolic protons); 8.48 (dd, $4 \mathrm{H}, H_{4^{\prime}}, H_{7^{\prime}}$, $H_{4}$, and $\left.H_{7}\right) ; 8.13\left(\mathrm{~s}, 2 \mathrm{H}, H_{\mathrm{b}}\right) ; 7.81\left(\mathrm{~s}, 2 \mathrm{H}, H_{\mathrm{d}}\right) ; 7.80\left(\mathrm{~s}, 2 \mathrm{H}, H_{5^{\prime}}\right.$ and $\left.H_{6^{\prime}}\right) ; 7.79\left(\mathrm{~s}, 2 \mathrm{H}, H_{5}\right.$ and $\left.H_{6}\right) ; 7.64\left(\mathrm{~d}, 2 \mathrm{H}, H_{3^{\prime}}\right.$ and $\left.H_{8^{\prime}}\right) ; 7.36$ (d, $2 \mathrm{H}, H_{3}$ and $\left.H_{8}\right) ; 7.07\left(\mathrm{~d}, 4 \mathrm{H}, H_{\mathrm{o}^{\prime}}\right) ; 6.74\left(\mathrm{~d}, 4 \mathrm{H}, H_{\mathrm{o}}\right) ; 5.82(\mathrm{~d}$, $\left.4 \mathrm{H}, H_{\mathrm{m}^{\prime}}\right) ; 5.67\left(\mathrm{~d}, 4 \mathrm{H}, H_{\mathrm{m}}\right) ; 5.04\left(\mathrm{~s}, 4 \mathrm{H}, H_{\mathrm{f}}\right) ; 4.69\left(\mathrm{~s}, 4 \mathrm{H}, H_{\mathrm{g}}\right)$; 4.80-3.00 (m, oligo(ethylene glycol) linker); 2.46 (s, 3H, $\mathrm{CH}_{3}$ group). MALDI-TOF: $m / z$ found 2295.2099 [M $\left.-\mathrm{PF}_{6}\right]^{+}$, calcd 2295.5363 for $\mathrm{C}_{146} \mathrm{H}_{84} \mathrm{~N}_{10} \mathrm{O}_{16} \mathrm{Cu}$.

[2]Catenate 14. This model compound was synthesized from precursor 5 and porphyrin 7. Final purification was achieved by column chromatography $\left(\mathrm{SiO}_{2}\right)$ using a gradient of $\mathrm{CH}_{2} \mathrm{Cl}_{2}-\mathrm{CH}_{3} \mathrm{OH}(98: 2 \mathrm{v} / \mathrm{v})$ as eluent, affording 14 as a greenish purple solid ( $0.065 \mathrm{~g}, 68 \%$ yield). ${ }^{1} \mathrm{H} \mathrm{NMR}\left(\mathrm{CDCl}_{3}\right), \delta \mathrm{ppm:} 8.96$ (s, $\left.1 \mathrm{H}, H_{\mathrm{a}}\right) ; 8.74(\mathrm{~d}, 4 \mathrm{H}$, pyrrolic protons); $8.60(\mathrm{~d}, 2 \mathrm{H}$, pyrrolic protons); 8.54 (d, $2 \mathrm{H}$, pyrrolic protons); 8.45 (dd, $4 \mathrm{H}, H_{4^{\prime}}, H_{7^{\prime}}$, $H_{4}$, and $\left.H_{7}\right) ; 8.16\left(\mathrm{~s}, 2 \mathrm{H}, H_{\mathrm{b}}\right) ; 7.82\left(\mathrm{~s}, 6 \mathrm{H}, H_{\mathrm{c}}\right.$ on MgP tert-butylphenyl groups); $7.81\left(\mathrm{~s}, 2 \mathrm{H}, H_{\mathrm{d}}\right) ; 7.78\left(\mathrm{~s}, 2 \mathrm{H}, H_{5^{\prime}}\right.$ and $\left.H_{6^{\prime}}\right)$; $7.75\left(\mathrm{~s}, 2 \mathrm{H}, H_{5}\right.$ and $\left.H_{6}\right) ; 7.68\left(\mathrm{~d}, 2 \mathrm{H}, H_{3^{\prime}}\right.$ and $\left.H_{8^{\prime}}\right) ; 7.60(\mathrm{~s}, 3 \mathrm{H}$, $H_{\mathrm{e}}$ on MgP-tert-butylphenyl group); 7.38 (d, $2 \mathrm{H}, H_{3}$ and $H_{8}$ ); $7.06\left(\mathrm{~d}, 4 \mathrm{H}, H_{\mathrm{o}^{\prime}}\right) ; 6.73\left(\mathrm{~d}, 4 \mathrm{H}, H_{\mathrm{o}}\right) ; 5.84\left(\mathrm{~d}, 4 \mathrm{H}, H_{\mathrm{m}^{\prime}}\right) ; 5.69$ $\left(\mathrm{d}, 4 \mathrm{H}, H_{\mathrm{m}}\right) ; 4.77\left(\mathrm{~s}, 4 \mathrm{H}, H_{\mathrm{g}}\right) ; 4.80-3.00(\mathrm{~m}$, oligo(ethylene glycol) linker); 1.58 (s, $54 \mathrm{H}$, tertbutyl $\mathrm{CH}_{3}$ groups). MALDI-TOF: $\mathrm{m} / \mathrm{z}$ found $2328.3825\left[\mathrm{M}-\mathrm{PF}_{6}\right]^{+}$, calcd 2328.0548 for $\mathrm{C}_{142} \mathrm{H}_{148} \mathrm{~N}_{14} \mathrm{O}_{12} \mathrm{MgCu}$.

[2]Catenate 15. This model compound was synthesized from precursor $\mathbf{5}$ and compound 9. Final purification was achieved by column chromatography $\left(\mathrm{SiO}_{2}\right)$ using a gradient of $\mathrm{CH}_{2} \mathrm{Cl}_{2}-\mathrm{CH}_{3} \mathrm{OH}(99: 1 \mathrm{v} / \mathrm{v})$ as eluent, affording 15 as a red solid (0.042 g, 70\% yield). ${ }^{1} \mathrm{H}$ NMR $\left(\mathrm{CDCl}_{3}\right), \delta \mathrm{ppm:} 8.16(\mathrm{~s}, 1 \mathrm{H}$, $\left.H_{\mathrm{a}}\right) ; 8.48\left(\mathrm{dd}, 4 \mathrm{H}, H_{4^{\prime}}, H_{7^{\prime}}, H_{4}\right.$, and $\left.H_{7}\right) ; 8.07$ (s, $\left.2 \mathrm{H}, H_{\mathrm{b}}\right) ; 7.78(\mathrm{~s}$, $2 \mathrm{H}, H_{5^{\prime}}$ and $\left.H_{6^{\prime}}\right) ; 7.67\left(\mathrm{~s}, 2 \mathrm{H}, H_{5}\right.$ and $\left.H_{6}\right) ; 7.51\left(\mathrm{~d}, 2 \mathrm{H}, H_{3^{\prime}}\right.$ and $\left.H_{8^{\prime}}\right) ; 7.42\left(\mathrm{~s}, 2 \mathrm{H}, H_{\mathrm{d}}\right) ; 7.32\left(\mathrm{~d}, 2 \mathrm{H}, H_{3}\right.$ and $\left.H_{8}\right) ; 7.07\left(\mathrm{~d}, 4 \mathrm{H}, H_{\mathrm{o}^{\prime}}\right)$; $6.74\left(\mathrm{~d}, 4 \mathrm{H}, H_{\mathrm{o}}\right) ; 5.82\left(\mathrm{~d}, 4 \mathrm{H}, H_{\mathrm{m}^{\prime}}\right) ; 5.67\left(\mathrm{~d}, 4 \mathrm{H}, H_{\mathrm{m}}\right) ; 4.62(\mathrm{~s}$, $4 \mathrm{H}, H_{\mathrm{g}}$ ); 4.80-3.00 (m, oligo(ethylene glycol) linker); 2.44 (s, $3 \mathrm{H}, \mathrm{CH}_{3}$ group). MALDI-TOF: $m / z$ found $1447.6229\left[\mathrm{M}-\mathrm{PF}_{6}\right]^{+}$, calcd 1447.5253 for $\mathrm{C}_{81} \mathrm{H}_{80} \mathrm{~N}_{10} \mathrm{O}_{12} \mathrm{Cu}$.

\section{Electrochemical and photophysical studies}

All solvents used were purchased from commercial suppliers (spectroscopic grade; 99.5\%) and used without further purification. A single-compartment, three electrode cell configuration was used for the square wave voltammetry measurements, using a glassy carbon electrode (3 mm diameter) as a working electrode, a platinum wire as a counter and a silver 
wire as a reference electrode. All electrochemical measurements were performed with a METROHM FRA $2 \mu$ Autolab Type III potentiostat. For the photophysical characterization the samples were placed in fluorimetric cuvettes with different pathways and, when necessary purged with molecular oxygen or argon. Steady-state UV-vis absorption spectroscopy was performed on a Lambda2 spectrometer (Perkin Elmer). Steady state fluorescence spectra were carried out at a FluoroMax3 spectrometer (Horiba) in the visible detection range and at a FluoroLog3 spectrometer (Horiba) with a IGA Symphony $(512 \times$ $1 \times 1 \mu \mathrm{m}$ ) detector in the NIR detection range (singlet oxygen quantum yields). Fluorescence lifetimes were determined by the time correlated single photon counting technique using a FluoroLog3 emission spectrometer (Horiba JobinYvon) equipped with an R3809U-58 MCP (Hamamatsu) and an $\mathrm{N}-405 \mathrm{LH}$ laser diode (Horiba JobinYvon) exciting at $403 \mathrm{~nm}$ (675 ps fwhm). Femtosecond transient absorption (TA) experiments were carried out with an amplified Ti:Sapphire laser system CPA-2110 fs laser (Clark MXR: output 775 nm, $1 \mathrm{kHz}$, and 150 fs pulse width) using a transient absorption pump/ probe detection system (TAPPS Helios, Ultrafast Systems). The $420 \mathrm{~nm}$ excitation wavelength was generated with a noncollinear optical parametric amplifier (NOPA, Clark MXR). For the, excitation wavelength the energy of $200 \mathrm{~nJ}$ per pulse was selected. Nanosecond transient absorption experiments were carried out with a Nd:YAG laser. The 532 and $355 \mathrm{~nm}$ excitation wavelength was formed by second and third harmonic generation, respectively. Pulse widths of $6 \mathrm{~ns}$ with energies of up to $10 \mathrm{~mJ}$ were selected. The optical detection was based on a pulsed Xenon lamp, a monochromator, a photomultiplier tube or a fast silicon photodiode with a $1 \mathrm{GHz}$ amplification and a $500 \mathrm{MHz}$ digital oscilloscope. The laser power of every laser pulse was registered using a bypath with a fast silicon photodiode. The experiments were performed on solutions in a $5 \times 10 \mathrm{~mm}$ quartz glass cuvette.

\section{Acknowledgements}

Financial support at Erlangen from Soltech is gratefully acknowledged. The authors at NYU gratefully acknowledge financial support from the U.S. National Science Foundation under grant CHE-0647334.

\section{Notes and references}

1 J. Deisenhofer and J. R. Norris, The Photosynthetic Reaction Center, Academic Press, New York, 1993.

2 D. M. Guldi, Chem. Soc. Rev., 2002, 31, 22.

3 J. Deisenhofer, O. Epp, I. Sinning and H. Michel, J. Mol. Biol., 1995, 246, 429.

4 J. Deisenhofer and H. Michel, Science, 1989, 245, 1463.

5 D. Gust, T. A. Moore and A. L. Moore, Acc. Chem. Res., 2001, 34, 40 .
6 D. Gust, T. A. Moore and A. L. Moore, Acc. Chem. Res., 2009, 42, 1890 .

7 J. D. Megiatto Jr., A. Antoniuk-Pablant, B. D. Sherman, G. Kodis, M. Gervaldo, T. A. Moore, A. L. Moore and D. Gust, Proc. Natl. Acad. Sci. U. S. A., 2012, 109, 15578.

8 P. L. Anelli, P. R. Ashton, R. Ballardini, V. Balzani, M. Delgado, M. T. Gandolfi, T. T. Goodnow, A. E. Kaifer, D. Philp, P. Marek, L. Prodi, M. V. Reddington, A. M. Z. Slawin, N. Spencer, J. F. Stoddart, C. Vicent and D. J. Williams, J. Am. Chem. Soc., 1992, 114, 193.

9 P. R. Ashton, V. Balzani, A. Credi, O. Kocian, D. Pasini, L. Prodi, N. Spencer, J. F. Stoddart, M. S. Tolley, M. Venturi, A. J. P. White and D. J. Williams, Chem. - Eur. J., 1998, 4, 590.

10 P.-R. Ashton, T. T. Goodnow, A. E. Kaifer, M. V. Reddington, A. M. Z. Slawin, N. Spencer, J. F. Stoddart, C. Vicent and D. J. Williams, Angew. Chem., Int. Ed. Engl., 1989, 28, 1396.

11 D. B. Amabilino, C. O. Dietrich-Buchecker, A. Livoreil, L. Pérez-García, J.-P. Sauvage and J. F. Stoddart, J. Am. Chem. Soc., 1996, 118, 3905.

12 Y.-Z. Hu, D. van Loyen, O. Schwarz, S. Bossmann, H. Dürr, V. Huch and M. Veith, J. Am. Chem. Soc., 1998, 120, 5822.

13 C. O. Dietrich-Buchecker and J.-P. Sauvage, Tetrahedron Lett., 1983, 24, 5095.

14 C. O. Dietrich-Buchecker and J.-P. Sauvage, J. Am. Chem. Soc., 1984, 106, 3043.

15 C. O. Dietrich-Buchecker and J.-P. Sauvage, Chem. Rev., 1987, 87, 795.

16 C. O. Dietrich-Buchecker and J.-P. Sauvage, Tetrahedron, 1990, 46, 503.

17 J.-P. Sauvage and C. O. Dietrich-Buchecker, Molecular Catenanes, Rotaxanes and Knots, Wiley VCH, Weinheim, Germany, 1999.

18 L. Flamigni, A. M. Talarico, J. C. Chambron, V. Heitz, M. Linke, N. Fujita and J.-P. Sauvage, Chemistry, 2004, 10, 2689.

19 L. Flamigni, A. M. Talarico, S. Serroni, F. Puntoriero, M. J. Gunter, M. R. Johnston and T. P. Jeynes, Chemistry, 2003, 9, 2649.

20 K. Li, P. J. Bracher, D. M. Guldi, M. A. Herranz, L. Echegoyen and D. I. Schuster, J. Am. Chem. Soc., 2004, 126, 9156.

21 K. Li, D. I. Schuster, D. M. Guldi, M. A. Herranz and L. Echegoyen, J. Am. Chem. Soc., 2004, 126, 3388.

22 J. D. Megiatto Jr., K. Li, D. I. Schuster, A. Palkar, M. A. Herranz, L. Echegoyen, S. Abwandner, G. Miguel and D. M. Guldi, J. Phys. Chem. B, 2010, 114, 14408.

23 J. D. Megiatto Jr., D. I. Schuster, S. Abwandner, G. de Miguel and D. M. Guldi, J. Am. Chem. Soc., 2010, 132, 3847.

24 J. D. Megiatto Jr., D. I. Schuster, G. de Miguel, S. Wolfrum and D. M. Guldi, Chem. Mater., 2012, 24, 2472.

25 J. D. Megiatto Jr., R. Spencer and D. I. Schuster, Org. Lett., 2009, 11, 4152. 
26 D. I. Schuster, K. Li, D. M. Guldi and J. Ramey, Org. Lett., 2004, 6, 1919.

27 L. Flamigni, V. Heitz and J.-P. Sauvage, Struct. Bonding, 2006, 121, 217.

28 T. J. Kesti, N. V. Tkachenko, V. Vehmanen, H. Yamada, H. Imahori, S. Fukuzumi and H. Lemmetyinen, J. Am. Chem. Soc., 2002, 124, 8067.

29 T. Umeyama and H. Imahori, J. Phys. Chem. C, 2013, 117, 3195.

30 R. A. Marcus, J. Chem. Phys., 1956, 24, 966.

31 D. M. Guldi and S. Fukuzumi, in Fullerenes From Synthesis to Optoelectronic Properties, ed. D. M. Guldi and N. Martin, Kluwer Academic Publishers, Dordrecht, 2002, p. 237.

32 H. Imahori and Y. Sakata, Adv. Mater., 1997, 9, 537.

33 D. M. Guldi, Chem. Commun., 2000, 321.

34 D. M. Guldi and M. Prato, Acc. Chem. Res., 2000, 33, 695.

35 S. Kirner, M. Sekita and D. M. Guldi, Adv. Mater., 2014, 26, 1482.

36 K. Kadish, E. Van Caemelbecke and G. Royal, in The Porphyrin Handbook, ed. K. M. Kadish, M. Smith and R. Guilard, Academic Press, New York, 2000.

37 M. E. El-Khouly, Y. Araki, O. Ito, S. Gadde, A. L. McCarty, P. A. Karr, M. E. Zandler and F. D'Souza, Phys. Chem. Chem. Phys., 2005, 7, 3163.

38 F. D’Souza, G. R. Deviprasad, M. E. Zandler, V. T. Hoang, A. Klykov, M. VanStipdonk, A. Perera, M. E. El-Khouly, M. Fujitsuka and O. Ito, J. Phys. Chem. A, 2002, 106, 3243.

39 F. D’Souza, M. E. El-Khouly, S. Gadde, A. L. McCarty, P. A. Karr, M. E. Zandler, Y. Araki and O. Ito, J. Phys. Chem. B, 2005, 109, 10107.

40 A. S. D. Sandanayaka, N. K. Subbaiyan, R. Chitta, Y. Araki, O. Ito and F. D'Souza, J. Porphyrins Phthalocyanines, 2008, 12, 857.

41 J. D. Megiatto Jr. and D. I. Schuster, in Handbook of Carbon Nano Materials, ed. F. D'Souza and K. M. Kadish, World Scientific Publishers, Singapore, 2011, vol. 1, p. 207.
42 R. Huisgen, Angew. Chem., Int. Ed. Engl., 1968, 7, 321.

43 H. C. Kolb, M. G. Finn and K. B. Sharpless, Angew. Chem., Int. Ed., 2001, 40, 2004.

44 C. W. Tornøe, C. Christensen and M. Meldal, J. Org. Chem., 2002, 67, 3057.

45 J. D. Megiatto Jr. and D. I. Schuster, New J. Chem., 2010, 34, 276.

46 J. D. Megiatto Jr., R. Spencer and D. I. Schuster, J. Mater. Chem., 2011, 21, 1544.

47 J. D. Megiatto Jr., D. Patterson, B. D. Sherman, T. A. Moore, D. Gust and A. L. Moore, Chem. Commun., 2012, 48, 4558.

48 L. Echegoyen and L. E. Echegoyen, Acc. Chem. Res., 1998, 31, 593.

49 A. Hirsch and M. Brettreich, Fullerenes: Chemistry and Reactions, Wiley-VCH, Weinheim, 2005.

50 F. D’Souza, G. R. Deviprasad, M. E. Zandler, M. E. ElKhouly, M. Fujitsuka and O. Ito, J. Phys. Chem. B, 2002, 106, 4952.

51 P. G. Seybold and M. Gouterman, J. Mol. Spectrosc., 1969, $31,1$.

52 Y.-P. Sun, G. E. Lawson, J. E. Riggs, B. Ma, N. Wang and D. K. Moton, J. Phys. Chem. A, 1998, 102, 5520.

53 C. Tanielian and C. J. Wolff, Phys. Chem., 1995, 99, 9825.

54 R. Schmidt and E. Afshari, J. Phys. Chem., 1990, 94, 4377.

55 C. Luo, D. M. Guldi, H. Imahori, K. Tamaki and Y. Sakata, J. Am. Chem. Soc., 2000, 122, 6535.

56 N. Armaroli, M. A. J. Rodgers, P. Ceroni, V. Balzani, C. O. Dietrich-Buchecker, J.-M. Kern, A. Bailal and J.-P. Sauvage, Chem. Phys. Lett., 1995, 241, 555.

57 T. Gunaratne, M. A. J. Rodgers, D. Felder, J.-F. Nierengarten, G. Accorsi and N. Armaroli, Chem. Commun., 2003, 3010. 